\title{
1 Enhanced bioproduction of poly-3-hydroxybutyrate from \\ 2 wheat straw lignocellulosic hydrolysates
}

4 M. Teresa Cesário ${ }^{a, *}$, Rodrigo S. Raposo ${ }^{a}$, M. Catarina M.D. de Almeida ${ }^{\text {a,c }}$,

5 Frederik van Keulen ${ }^{b}$, Bruno S. Ferreira ${ }^{b}$, M. Manuela R. da Fonseca ${ }^{a}$

6

7 a IBB-Institute for Biotechnology and Bioengineering, Instituto Superior Técnico, Av. Rovisco

8 Pais, 1049-001 Lisboa, Portugal

9 'Biotrend- Inovação e Engenharia em Biotecnologia, S.A., Biocant Park, Núcleo 04 - Lote 2,

10 3060-197 Cantanhede, Portugal

11 'CIIEM-Centro de Investigação Interdisciplinar Egas Moniz, ISCSEM, Campus Universitário,

12 Quinta da Granja, 2829-511 Monte de Caparica, Portugal

\section{Abstract}

14 Polyhydroxyalkanoates (PHAs) are bioplastics that can replace conventional

15 petroleum derived products in various applications. One of the major barriers for

16 their widespread introduction in the market is the higher production costs when

17 compared with their petrochemical counterparts. In this work, a process was

18 successfully implemented with high productivity based on wheat straw, a cheap

19 and readily available agricultural residue, as raw material. The strain

20 Burkholderia sacchari DSM 17165 which is able to metabolize glucose, xylose

21 and arabinose, the main sugars present in wheat straw hydrolysates (WSH),

22 was used. Results in shake flask showed that $B$. sacchari cells accumulated ca

\footnotetext{
* Corresponding author. Tel.: +35121 8419137; fax: +351218419062.

e-mail address: teresa.cesario@ist.utl.pt
} 
$2370 \% \mathrm{~g} \mathrm{P}(3 \mathrm{HB}) / g$ cell-dry-weight with a yield of polymer on sugars $\left(\mathrm{Y}_{\mathrm{P} / \mathrm{S}}\right)$ of 0.18

$24 \mathrm{~g} / \mathrm{g}$ when grown on a mixture of commercial C6 and C5 sugars (control), while

25 these values reached ca $60 \% \mathrm{~g} \mathrm{P}(3 \mathrm{HB}) / \mathrm{g}$ cell-dry-weight and $0.19 \mathrm{~g} / \mathrm{g}$,

26 respectively, when WSHs were used as carbon source. In fed-batch cultures

27 carried out in $2 \mathrm{~L}$ stirred tank reactors on $\mathrm{WSH}$, a maximum polymer

28 concentration of $105 \mathrm{~g} / \mathrm{L}$ was reached after $61 \mathrm{~h}$ of cultivation corresponding to

29 an accumulation of $72 \%$ of CDW. Polymer yield and productivity were $0.22 \mathrm{~g}$

$30 \mathrm{P}(3 \mathrm{HB}) / \mathrm{g}$ total sugar consumed and $1.6 \mathrm{~g} / \mathrm{L} \cdot \mathrm{h}$, respectively. The selected

31 feeding strategy successfully overcame the carbon catabolite repression

32 phenomenon observed in sugar mixtures containing hexoses and pentoses.

33 This is the first work describing fed-batch cultivations aiming at PHA production

34 using real lignocellulosic hydrolysates. Additionally, the $\mathrm{P}(3 \mathrm{HB})$ volumetric

35 productivities attained are, by far, the highest achieved ever on agricultural

36 wastes hydrolysates.

\section{Keywords}

38 Wheat straw hydrolysates; poly 3-hydroxybutyrate; Burkholderia sacchari; carbon

39 catabolite repression; agricultural lignocellulosic residues; high cell density cultures

\section{Introduction}

42 The widespread use of synthetic, petroleum-derived plastics has

43 generated an environmental problem because these materials resist

44 degradation and accumulate in the environment.

$45 \quad$ PHAs are biologically produced macromolecules (polyesters with

46 molecular weights from $5 \times 10^{4}$ to $2 \times 10^{6} \mathrm{Da}$ [1]) with a wide range of

47 properties that find applications as biodegradable and biocompatible

48 thermoplastics. They are synthesized by many microbial strains under

49 unbalanced growth conditions such as the presence of excess carbon source

50 and limitation of at least one essential nutrient e.g. phosphorous, nitrogen, 
51 sulphur, magnesium or oxygen [2-3]. These polymeric chains are stored in the

52 cytoplasm as granules and function as carbon and energy storage materials.

53 The current high production costs make PHAs more expensive than

54 conventional plastics. In 2011, the prices for PHAs were in the range of 3.7-4.5

55 Euro $/ \mathrm{kg}$, while conventional polyolefins such as polyethylene terephtalate and

56 polystyrene were in the range of $1.38-1.63$ Euro/kg

57 (http://www.icis.com/Articles/2011/02/15/9433445/pha-shows-great-promise-in-

58 packaging-applcation.html). One factor that significantly contributes to the

59 overall PHA production costs is the price of the carbon source [4]. Most of the

60 carbon sources used for PHA production are noble sources such as pure

61 carbohydrates (glucose, sucrose), alkanes and fatty acids. In order to reduce

62 the raw materials costs, inexpensive carbon sources like industrial by-products

63 such as waste glycerol [5], cheese whey [6] and waste plastics [7] or

64 agricultural residues like sugar cane bagasse [8-9], sawdust [10] or forest

65 biomass [11] have been tested as substrates [12]. This approach has the

66 concomitant advantage of converting waste materials into value-added

67 products.

68 Lignocellulosic materials such as agricultural by-products and forestry residues

69 are renewable inexpensive sources of carbohydrates that have no competing

70 food value. These materials consist mainly of cellulose, hemicellulose and

71 lignin. Cellulose and hemicellulose constitute an excellent source of carbon to

72 be used in different biological processes after hydrolysis to monomeric sugars.

73 Cellulose is a highly crystalline linear polymer of $\beta-D-$ glucopyranose units,

74 joined together in long chains. Hemicellulose is a branched polysaccharide that

75 consists of pentoses, mainly xylose and arabinose, and hexoses such as 
76 glucose, galactose and mannose. Cellulose and hemicellulose are embedded in

77 a complex lignin matrix which acts as a binder, conferring to plants structural

78 support, impermeability and resistance against microbial attack and oxidative

79 stress.

80 Agricultural lignocellulosic residues such as wheat or rice straw are abundant

81 feedstocks that have low economic value and are normally used as cattle feed.

82 According to the FAO Cereal Supply and Demand Brief

83 (http://www.fao.org/worldfoodsituation/wfs-home/csdb/en/), the world wheat

84 production estimated for the period 2012- 2013 is about 660 million tonnes of

85 which about $15-20 \%$ is straw [14]. Asia and Europe are the primary production

86 regions, with about $43 \%$ and $32 \%$, respectively, while North America is the third

87 largest production region with $15 \%$ of global wheat production [15].

88 These agricultural wastes are a potential source of carbohydrates and can thus

89 be upgraded namely in the production of PHAs. In this work, wheat straw

90 hydrolysates (WSH) produced by biorefinery.de GmbH (Teltow, Germany) using

91 the AFEX (Ammonium Fiber Expansion) technology as pre-treatment [16-17],

92 were assayed as carbon source, in the context of the European research

93 project BUGWORKERS (www.bugworkersproject.eu/).AFEX is particularly

94 suited for herbaceous and agricultural residues [18-19], works only moderately

95 well on hardwoods and is not attractive for softwoods [18, 20]. The moderate

96 conditions of the AFEX treatment minimize formation of sugar degradation

97 products [18] such as organic acids (e.g. acetic and formic acid), furaldehydes

98 (e.g. furfural, hydroxymethylfurfural) and aromatic compounds (derived from

99 lignin degradation) which are inhibitory to microbial species. 
Although the use of lignocellulosic derived carbon sources for the

101 production of biocommodities such as PHAs is an appealing concept, few works

102 are described in literature showing promising results. The economical feasibility

103 of such a system strongly depends on the ability of the strains to consume both

104 C6 and C5 sugars, with high uptake rates, and to accumulate high amounts of

105 PHAs with high yields in a short time. Moreover, in order to achieve high

106 volumetric productivities, a system featuring high-cell-density cultures [2, 5] is

107 essential.

108 In the present work, Burkholderia sacchari DSM 17165, a strain able to

109 accumulate PHAs upon consumption of glucose, xylose and arabinose [9, 21],

110 the main sugars present in wheat straw hydrolysates (WSH), was selected. For

111 the first time a fed-batch cultivation process featuring high productivities and

112 conversion yields of $\mathrm{P}(3 \mathrm{HB})$ based on a lignocellulosic agricultural residue is 113 described.

\section{Materials and Methods}

115 Microorganisms and media

116 Burkholderia sacchari DSM 17165, a strain able to grow on the main

117 sugars present in the wheat straw hydrolysates and to accumulate PHAs, was

118 used throughout this work.

119 The medium for the seed and flask cultures was (per liter): $\left(\mathrm{NH}_{4}\right)_{2} \mathrm{SO}_{4}, 1.0$ $120 \mathrm{~g} ; \mathrm{Na}_{2} \mathrm{HPO}_{4} .2 \mathrm{H}_{2} \mathrm{O}, 4.5 \mathrm{~g} ; \mathrm{KH}_{2} \mathrm{PO}_{4}, 1.5 \mathrm{~g} ; \mathrm{MgSO}_{4} .7 \mathrm{H}_{2} \mathrm{O}, 0.2 \mathrm{~g}$; yeast extract, 1.0

$121 \mathrm{~g}$ and a trace elements solution [2], $1.0 \mathrm{~mL}$. The composition of this medium

122 was designed for nitrogen to be the first limiting nutrient. The $\mathrm{MgSO}_{4} \cdot 7 \mathrm{H}_{2} \mathrm{O}$

123 solution was autoclaved separately. The carbon source (noble sugars solution 
124 or WSHs) was pasteurized at $70^{\circ} \mathrm{C}$ for two hours. Sterilization at $121^{\circ} \mathrm{C}$ was not

125 used to avoid thermal degradation of the sugars. Both the carbon source and

126 the $\mathrm{MgSO}_{4} \cdot 7 \mathrm{H}_{2} \mathrm{O}$ solutions were aseptically added to the medium.

127 The initial medium composition for the fed-batch culture was (per liter):

$128\left(\mathrm{NH}_{4}\right)_{2} \mathrm{SO}_{4}, 4.0 \mathrm{~g} ; \mathrm{KH}_{2} \mathrm{PO}_{4}, 3.0 \mathrm{~g}$; citric acid, $1.7 \mathrm{~g}$; EDTA, $40 \mathrm{mg}$; trace

129 elements solution [2], $10 \mathrm{~mL} ; \mathrm{MgSO}_{4} .7 \mathrm{H}_{2} \mathrm{O}, 1.2 \mathrm{~g}$. The $\mathrm{pH}$ was adjusted to 6.8

130 with $\mathrm{KOH}(5 \mathrm{~N})$. WSHs or a solution containing a blend of sugars simulating the

131 hydrolysate composition were used as feeding during the fed-batch phase.

Carbon sources

133 The lignocellulosic hydrolysates were prepared by biorefinery. de $\mathrm{GmbH}$

134 (Teltow, Germany) from grounded wheat straw using the AFEX process as pre-

135 treatment followed by an enzymatic hydrolysis of the cellulose and

136 hemicellulose fractions [22]. The composition of hydrolysate A (Table 1) is

137 representative of the hydrolysates prepared by this methodology. The

138 concentration of inhibitors in the hydrolysates, namely formic and acetic acids

139 and aldehydes such as furfural and hydroxymethyl furfural (HMF) was found to

140 be negligible. Improvement of the WSH composition has been progressively

141 carried out by biorefinery.de $\mathrm{GmbH}$ as a direct result of the feedback from the

142 PHA production assays. For instance, the amount of citrate initially used by

143 biorefinery.de. $\mathrm{GmbH}$ as buffer in the enzymatic step leading to citrate-rich

144 hydrolysates (hydrolysates A and B; Table 1) was substantially reduced (see

145 Results and Discussion) yielding WSH with negligible citrate concentrations

146 (hydrolysates $\mathrm{C}$ to $\mathrm{H}$; Table 1).Moreover, the working volume limit of the

147 reactors for PHA production demanded concentrated WSH to be used as 
148 bioreactor feed. For this purpose biorefinery.de $\mathrm{GmbH}$ has concentrated some

149 of the hydrolysates 10 fold by evaporation ( $\mathrm{B}$ to $\mathrm{H}$; Table 1 ).

150 Strain storage and inoculum preparation

151 Cultures of $B$. sacchari were stored at $-80^{\circ} \mathrm{C}$ in $2 \mathrm{~mL}$ cryovials containing

$152300 \mu \mathrm{L}$ of glycerol and $1500 \mu \mathrm{L}$ of a previously grown liquid culture in the late

153 exponential phase prepared with seeding medium [2] and supplemented with 20

$154 \mathrm{~g} / \mathrm{L}$ of xylose. The inocula for the shake flask experiments were prepared by

155 transferring the content of the cryovials to $500 \mathrm{~mL}$ shake flasks containing 50

$156 \mathrm{~mL}$ of seeding medium supplemented with $10 \mathrm{~g} / \mathrm{L}$ of glucose or xylose, and

157 incubated at $30^{\circ} \mathrm{C}$ in an orbital incubator (Infors AG, Switzerland) at $170 \mathrm{rpm}$ for 15812 hours.

159 Culture conditions

160 Shaking flask cultivations

161 Shaking flask trials were performed in order to determine the growth,

162 consumption and production parameters of Burkholderia sacchari DSM 17165

163 using glucose, xylose and arabinose as single sugars or sugar mixtures. The

164 experiments were carried out in $500 \mathrm{~mL}$ baffled conical flasks containing 100

$165 \mathrm{~mL}$ of liquid phase. The inoculum varied in the range 5 to $10 \%(\mathrm{v} / \mathrm{v})$ so as to

166 obtain identical initial optical densities $\left(O D_{\text {initial }}\right.$ ca. 0.3$)$. Different concentrations

167 of sugars or blends of sugars were used.

168 Shaking flask experiments were also carried out to compare growth and

169 production on the WSH with those attained on a blend of sugars (control)

170 simulating the sugar composition of the WSH. The trace elements solution, the 
$171 \mathrm{MgSO}_{4} .7 \mathrm{H}_{2} \mathrm{O}$ solution and the $\mathrm{WSH}$ or the control were added separately to 500

$172 \mathrm{~mL}$ flasks to make up a total working volume of $100 \mathrm{~mL}$. The WSHs were

173 neutralized with $5 \mathrm{M} \mathrm{KOH}$ to a pH of 6.8 prior to use. These assays were

174 performed in duplicate and the average value was considered.

\section{Fed-batch cultivations}

176 Fed-batch cultivations were carried out in 2L stirred-tank reactors (STRs)

177 (New Brunswick Bioflo 115) operated using the BioCommand Batch Control

178 software which enabled control, monitoring and data acquisition. The $\mathrm{pH}$ was

179 controlled at 6.8 with $28 \% \mathrm{NH}_{4} \mathrm{OH}$ and $2 \mathrm{M} \mathrm{HCl}$ solutions. The aeration rate

180 used was $3.6 \mathrm{~L}_{\text {air }} / \mathrm{min}$ and the temperature $32^{\circ} \mathrm{C}$. The dissolved oxygen set-

181 point was $20 \%$ saturation and the maximum agitation speed was $1200 \mathrm{rpm}$.

182 The inoculum (10\% v/v) was prepared using a pair of $500 \mathrm{~mL}$ baffled flasks

183 containing $75 \mathrm{~mL}$ of seeding medium. Each flask was inoculated with one

184 cryovial, supplemented with $20 \mathrm{~g} / \mathrm{L}$ of glucose and incubated during $12 \mathrm{~h}$ at 30

$185{ }^{\circ} \mathrm{C}$ and $170 \mathrm{rpm}$. The initial volume of the fed-batch culture was $1.5 \mathrm{~L}$.

186 Feeding was triggered by the decrease in the stirring speed which resulted

187 from the carbon source exhaustion in the medium. The feeding solution

188 consisted either of a solution of glucose, xylose and arabinose with the same

189 composition of the hydrolysate or the real WSH. To promote polymer

190 accumulation, phosphate limitation was imposed by limiting the initial phosphate

191 concentration in the medium $\left(\mathrm{KH}_{2} \mathrm{PO}_{4} ; 3 \mathrm{~g} / \mathrm{L}\right)$. Under these cultivation

192 conditions, phosphate became the limiting substrate when the cell concentration

193 reached approximately $35 \mathrm{~g} / \mathrm{L}$ cell dry weight (CDW). Culture samples were 
194 periodically harvested in order to analyze biomass, polymer and sugar

195 concentrations.

196 Analytical methods

197 Cellular growth was monitored off-line by measuring the OD of samples at $198600 \mathrm{~nm}$ in a double beam spectrophotometer (Hitachi U-2000). Cell dry weight 199 (CDW) was determined by centrifuging $1.2 \mathrm{~mL}$ of culture broth in a Sigma 1-15

$200 \mathrm{P}$ microcentrifuge (9168 $\times \mathrm{g}$ during $4 \mathrm{~min}$ ) using a previously dried and weighted

201 microtube. The pellet was washed with distilled water and dried at $62 \stackrel{\circ}{ } \mathrm{C}$ in a 202 Memmert oven (Model 400) until constant weight.

203 For $\mathrm{P}(3 \mathrm{HB})$ determination, $1.2 \mathrm{~mL}$ aliquots of culture medium were

204 withdrawn from the broth and centrifuged. The pellet was frozen after being 205 washed with distilled water. This pellet was then subjected to acidic 206 methanolysis [23].Samples of the organic phase were analyzed in a gas 207 chromatograph (Agilent Technologies 5890 series II) equipped with a FID 208 detector and a 7683B injector. The capillary column was a HP-5 from Agilent 209 J\&W Scientific, $30 \mathrm{~m}$ in length and $0.32 \mathrm{~mm}$ of internal diameter. The oven, 210 injector and detector temperatures were kept constant at $60{ }^{\circ} \mathrm{C}, 120{ }^{\circ} \mathrm{C}$ and 150

$211 \stackrel{\circ}{\circ}$, respectively. Data acquisition and integration were performed by a

212 Shimadzu CBM-102 communication Bus Module and Shimadzu GC Solution

213 software (Version 2.3), respectively. Peak identification was achieved using as

214 standard 3-methyl hydroxybutyrate (Sigma). Calibration curves were obtained

215 using samples of $\mathrm{P}(3 \mathrm{HB})$ produced previously which were subjected to the 216 same methylation process as the cells. 
217 Glucose, xylose and arabinose as well as organic acids, furaldehydes and 218 phosphate concentrations were determined by HPLC (Hitachi LaChrom Elite)

219 equipped with a Rezex ROA-Organic acid $\mathrm{H}^{+} 8 \%$ (300 mm x $7.8 \mathrm{~mm}$ ) column,

220 an auto sampler (Hitachi LaChrom Elite L-2200), a HPLC pump (Hitachi

221 LaChrom Elite L-2130), a Hitachi L-2490 refraction index detector for sugar and

222 phosphate and a Hitachi L-2420 UV-Vis detector for organic acids and

223 furaldehydes. A column heater for larger columns (Croco-CIL 100-040-220P, 40

$224 \times 8 \times 8 \mathrm{~cm}, 30^{\circ} \mathrm{C}-9^{\circ} \mathrm{C}$ ) was connected externally to the HPLC system. The

225 injection volume was $20 \mu \mathrm{L}$ and elution was achieved using a $5 \mathrm{mM}$ solution of

$226 \mathrm{H}_{2} \mathrm{SO}_{4}$. The column was kept at $65^{\circ} \mathrm{C}$ and the pump operated at a flow rate of

$2270.5 \mathrm{~mL} / \mathrm{min}$.

228 Nitrogen and phosphorous were determined by the methods described in

229 Greenberg, AE. et al, 1992 [24].

\section{Results and Discussion}

\section{Shaking flask cultivations}

232 Strain selection, growth and $P(3 H B)$ production on commercial sugars

233 Wheat straw contains ca $25 \%(\mathrm{w} / \mathrm{w})$ of hemicellulose on a dry weight basis of

234 which ca $80 \%$ are pentoses [25].The economic feasibility of processes using

235 WSHs as carbon sources to produce PHAs strongly depends on the ability of

236 microorganisms to consume both the hexoses and pentoses and to convert

237 these sugars into PHA at high conversion yields ( $\mathrm{Y}_{\mathrm{P} / \mathrm{S}} ; \mathrm{g}$ polymer $/ \mathrm{g}$ sugar $)$ and

238 consumption rates $\left(q_{s} ; g_{\text {sugar }} / g_{c e l l} \cdot h\right)$. This is crucial both to increase the total

239 carbon up-take by the cells and to avoid pentose accumulation in the broth

240 which may reach inhibitory concentrations. 
241 Only few strains have been described in literature as being able to

242 metabolize pentoses and accumulate PHAs. Table 2 gives an overview of the

243 wild and recombinant bacterial strains able to metabolize xylose (the

244 predominant pentose in WSHs) reported so far. Based on these data

245 Burkholderia sacchari IPT 101 (B. sacchari DSM 17165) a strain able to

246 accumulate high $\mathrm{P}(3 \mathrm{HB})$ amounts and which shows high yields of polymer on

247 xylose (Lopes et al 2009), was selected to be used throughout this work.

248 Growth and $\mathrm{P}(3 \mathrm{HB})$ production were followed with $B$. sacchari using

249 different concentrations of glucose (10 and $20 \mathrm{~g} / \mathrm{L})$, xylose (10 and $20 \mathrm{~g} / \mathrm{L}$ ) and

250 arabinose $(20 \mathrm{~g} / \mathrm{L})$ and a mixture of glucose and xylose $(10 \mathrm{~g} / \mathrm{L}$ glucose $+10 \mathrm{~g} / \mathrm{L}$

251 xylose). The results for some of these cultivations are shown in Fig. 1. In these

252 assays cell growth occurred until nitrogen in the medium became exhausted

253 and polymer started to accumulate within the cells (at a CDW of approximately

$2543 \mathrm{~g} / \mathrm{L})$. For the calculation of the $\mathrm{P}(3 \mathrm{HB})$ yield on sugars $\left(\mathrm{Y}_{\mathrm{P} / \mathrm{s}} ; \mathrm{g}_{\mathrm{pol}} / \mathrm{g}_{\text {sugar }}\right)$,

$255 \mathrm{P}(3 \mathrm{HB})$ volumetric productivity ( Prod $_{\mathrm{vol}} ; \mathrm{g} /(\mathrm{L} \mathrm{h})$ ) and $\mathrm{P}(3 \mathrm{HB})$ cell content ( \% ;

$\left.256 \mathrm{~g}_{\mathrm{pol}} / \mathrm{g}_{\mathrm{CDW}}\right)$, the maximum $\mathrm{P}(3 \mathrm{HB})$ concentration in each assay, its

257 corresponding biomass concentration and total sugar consumption were

258 considered.

259 The results are reported on Table 3. For the single sugar assays using 20

$260 \mathrm{~g} / \mathrm{L}$ glucose, xylose and arabinose, all cultures showed a similar yield of

261 polymer on sugar consumed (YP/S) with a value of ca $0.25 \mathrm{~g} \mathrm{P}(3 \mathrm{HB}) / \mathrm{g}$ sugar.

262 However, the volumetric productivities are approximately $50 \%$ higher in the

263 case of glucose $(0.13 \mathrm{~g} /(\mathrm{L} \mathrm{h}))$, compared to the productivities on xylose $(0.08$

$264 \mathrm{~g} /(\mathrm{L} h))$ and on arabinose $(0.09 \mathrm{~g} /(\mathrm{L} h))$. Similar results have been reported by

265 Lopes et al, 2009, who claimed that this might be explained by the theoretical 
266 ATP/3HB monomer ratio being $3 \mathrm{~mol} / \mathrm{mol}$ in the case of xylose compared to a

267 value of $7 \mathrm{~mol}$ ATP/ mol 3HB in the case of glucose [26]. In sugar mixtures

268 containing $10 \mathrm{~g} / \mathrm{L}$ glucose and $10 \mathrm{~g} / \mathrm{L}$ xylose, the strain preferentially consumed

269 glucose and delayed the use of xylose (Fig.1). These results are ascribed to

270 carbon catabolite repression (CCR); i.e., in the presence of sugar mixtures, a

271 preferential consumption of one of the sugars is observed. This is a major

272 problem when dealing with lignocellulosic hydrolysates as fermentation

273 substrates because of incomplete sugar conversion. In some strains CCR is

274 mediated by proteins of the phosphotransferase system (PTS). Lopes et al.,

275 2011, studied catabolite repression in PTS mutants of Burkholderia sacchari

276 IPT101 in order to improve total carbon up-take in sugar mixtures [27]. The wild

277 strain only started consuming xylose after glucose was completely depleted,

278 while one U.V. mutant was able to consume glucose and xylose simultaneously.

279 At a shaking flask scale, in a medium supplemented with $1 \mathrm{~g} / \mathrm{L}$ of yeast extract,

280 this mutant showed a specific growth rate, a volumetric productivity and a

$281 \mathrm{PHA} /$ carbon yield of $0.43 \mathrm{~h}^{-1}, 0.12 \mathrm{~g} /(\mathrm{L} \mathrm{h})$ and $0.23 \mathrm{~g} / \mathrm{g}$, respectively. As

282 compared to its wild strain counterpart, the values were, respectively, $0.41 \mathrm{~h}^{-1}$,

$2830.11 \mathrm{~g} /(\mathrm{L} \mathrm{h})$ and $0.25 \mathrm{~g} / \mathrm{g}$. These authors have studies under way to further

284 overcome catabolite repression in B. sacchari.

285 In the present work the efforts have been focused on the development of 286 high cell density fed-batch cultivations of $B$. sacchari DSM 17165 wild strain, at

287 bench-scale, aiming at reaching high volumetric productivities on WSHs. For

288 this purpose, and since the rate of pentose consumption is much affected by the 289 presence of glucose, feeding strategies needed to be sought to enhance the 
290 productivity and to avoid the accumulation of xylose and arabinose up to

291 potentially inhibiting concentrations.

\section{Inhibition studies}

293 Inhibition trials were thus carried out to check the inhibitory effect of

294 glucose and xylose concentrations on $B$. sacchari growth and polymer

295 accumulation. Each sugar was tested separately in shaking flasks containing

296 the seeding medium. The maximum specific growth rate $\left(\mu_{\max }\right)$ was assessed

297 for glucose and xylose in the range of concentrations usually encountered in the

298 bioreactor (10-60 g/L glucose and 10-30 g/L xylose). No growth inhibition was

299 observed up to $60 \mathrm{~g} / \mathrm{L}$ on glucose $\left(\mu_{\max }\right.$ varied between $0.28 \mathrm{~h}^{-1}$ for $10 \mathrm{~g} / \mathrm{L}$

300 glucose and $0.27 \mathrm{~h}^{-1}$ for $60 \mathrm{~g} / \mathrm{L}$ glucose) and up to $30 \mathrm{~g} / \mathrm{L}$ on xylose ( $\mu_{\max }$ varied

301 between $0.21 \mathrm{~h}^{-1}$ for $10 \mathrm{~g} / \mathrm{L}$ xylose to $0.18 \mathrm{~h}^{-1}$ for $30 \mathrm{~g} / \mathrm{L}$ xylose).

The maximum specific growth rate and $\mathrm{P}(3 \mathrm{HB})$ production of $B$. sacchari

303 were studied in media containing $10 \mathrm{~g} / \mathrm{L}$ glucose and increasing concentrations

304 of xylose $(0-80 \mathrm{~g} / \mathrm{L})$ thus mimicking the accumulation of xylose that could occur

305 in fed-batch cultivations. The assays were followed during $30 \mathrm{~h}$. The maximum

306 specific growth rate was independent of the xylose concentration up to $30 \mathrm{~g} / \mathrm{L}$

307 xylose $\left(\mu \approx 0.30 \mathrm{~h}^{-1}\right)$ and decreased at higher xylose concentrations. The highest

308 final $\mathrm{P}(3 \mathrm{HB})$ concentration of $3.8 \mathrm{~g} / \mathrm{L}$ was obtained at an initial concentration of

$30920-30 \mathrm{~g} / \mathrm{L}$ xylose. At higher xylose concentrations up to $80 \mathrm{~g} / \mathrm{L}$, the final $\mathrm{P}(3 \mathrm{HB})$

310 concentration remained constant at approximately $2.0 \mathrm{~g} / \mathrm{L}$. After $30 \mathrm{~h}$ the

311 glucose present in the medium was completely consumed in all the flasks, while

312 the amount of xylose consumed was constant (about $8.5 \mathrm{~g} / \mathrm{L}$ ) for initial xylose

313 concentrations up to $40 \mathrm{~g} / \mathrm{L}$, decreasing for higher xylose concentrations. The 
314 highest product yield on C-source was obtained in the absence of xylose (0.24

$315 \mathrm{~g} / \mathrm{g} \mathrm{C}$-source). In the range of $40-80 \mathrm{~g} / \mathrm{L}$ xylose the yield decreased to a fairly

316 constant value of $0.12 \mathrm{~g} / \mathrm{g} \mathrm{C}$-source. This observation might be ascribed to a

317 decrease of the $\mathrm{pH}$ in the cultivation medium to a value of circa 4.8, which is

318 due to the presence of an unidentified acid (detected by HPLC) accumulating in

319 the medium that apparently inhibits the metabolic activity.

320 This set of experiments indicated that B. sacchari DSM 17165 is able to

321 withstand relatively high xylose concentrations without significant loss of

322 activity.

323 Growth and production on wheat straw hydrolysates

324 Shaking flask experiments were carried out to study growth and $\mathrm{P}(3 \mathrm{HB})$

325 production by $B$. sacchari on WSHs. Hydrolysate A (Table 1) containing 32.4

$326 \mathrm{~g} / \mathrm{L}$ glucose, $12.9 \mathrm{~g} / \mathrm{L}$ xylose and $4.5 \mathrm{~g} / \mathrm{L}$ arabinose was tested as C-source and

327 compared to a control (simulated hydrolysate) where the C-source was a

328 mixture of sugars (glucose, xylose and arabinose) with the same concentrations

329 as the hydrolysate. Biomass growth, $\mathrm{P}(3 \mathrm{HB})$ production and sugar

330 consumptions were followed during the time course of the cultivations. The

331 results are shown in Fig. 2. Production parameters (Table 4) were calculated for

332 each assay based on the maximum polymer concentrations, corresponding

333 biomass concentrations and total sugar consumptions. It is observed that even

334 though similar total biomass concentrations (CDW) were achieved with

335 hydrolysate $A$ and control (CDW $=7.0 \mathrm{~g} / \mathrm{L}$ and $6.0 \mathrm{~g} / \mathrm{L}$, respectively), the total

336 amount of sugars consumed is much lower on hydrolysate $A(12.5 \mathrm{~g} / \mathrm{L})$ than on

337 the sugar blend $(24 \mathrm{~g} / \mathrm{L})$. This suggests that on hydrolysate A biomass is 
338 preferentially being produced from a carbon source other than sugars. This is

339 reflected in the value of the yield of residual biomass on sugar. Residual

340 biomass ( $\mathrm{X}$ res) was calculated by the difference of the total biomass dry weight

341 and the concentration of polymer $(\mathrm{X}$ res $=\mathrm{CDW}-\mathrm{P}(3 \mathrm{HB}))$. Growth on this $\mathrm{C}$ -

342 source is however not translated into polymer production, since the amount of

$343 \mathrm{P}(3 \mathrm{HB})$ produced is proportional to the amount of glucose, $x y l o s e$ and

344 arabinose being consumed and that is reflected on the similar value of yield of

345 polymer on these sugars $\left(\mathrm{Y}_{\mathrm{P}(3 \mathrm{HB}) / \mathrm{sugars}}=0.19 \mathrm{~g} / \mathrm{g}\right)$, both for the control and the

346 hydrolysate. This value is similar to the results obtained by Silva et al (2004) for

347 the same strain.

348 These results suggest that there might be other C-sources in the

349 hydrolysate besides sugars which are not used for polymer production. To verify

350 this hypothesis, the hydrolysate was diluted two fold to decrease the

351 concentration of these unknown components. Table 4 shows that upon dilution

352 of the hydrolysate, the total amount of consumed sugars nearly doubled and the

353 same applies to the concentration of $\mathrm{P}(3 \mathrm{HB})$. These results support the

354 hypothesis of the presence in the WSHs of one or more compounds which are

355 uptaken prior to glucose, xylose and arabinose. One of these compounds is

356 probably citrate which was used as buffer in the enzymatic step of the

357 production of the hydrolysate. Citrate is rapidly consumed since it enters easily

358 the Krebs cycle without the need of being metabolized as the reducing sugars

359 do. 
361 The results and discussion in the previous section confirmed Burkholderia 362 sacchari DSM 17165 as a good candidate for the bioreactor studies. Stimulation 363 of $\mathrm{P}(3 \mathrm{HB})$ biosynthesis has been achieved through the limited availability of

364 several nutrients in the medium namely nitrogen, phosphorous, oxygen, magnesium. Previous experiments have been performed to determine which limiting nutrient maximizes polymer accumulation. Higher $\mathrm{P}(3 \mathrm{HB})$ productivities

367 were obtained when P-limitation was used compared to the N-limitation (data 368 not shown). The combined effect of a larger productivity and the need of less 369 phosphate (lower raw-material costs) was the key for choosing P-limitation to 370 trigger polymer accumulation. In order to better understand the dynamics of sugar consumption in the

373 STR, B. sacchari was cultivated fed-batchwise in a synthetic medium containing

374 a mixture of glucose $(9 \mathrm{~g} / \mathrm{L})$, xylose $(8 \mathrm{~g} / \mathrm{L})$ and arabinose $(2 \mathrm{~g} / \mathrm{L})$ as C-sources.

375 The cultures were inoculated with a $24 \mathrm{~h}$ grown shake flask culture. Glucose 376 and citrate were consumed preferentially, while xylose and arabinose were only 377 consumed when the glucose concentration was low (Fig. 3). The maximum 378 specific growth rate during the exponential growth phase (before polymer 379 accumulation began).was $0.21 \mathrm{~h}^{-1}$. Approximately twenty hours after 380 inoculation, a $9 \mathrm{~mL}$ pulse of a solution containing glucose, xylose and arabinose

381 (250, 200 and $50 \mathrm{~g} / \mathrm{L}$, respectively), was manually fed and the sugar

382 consumption was followed. Glucose was consumed rapidly (accompanied by an 383 increased stirring speed, indicating high metabolic activity) while xylose and 384 arabinose consumption proceeded at a lower rate (stirring speed goes to a 
385 lower plateau upon glucose exhaustion since less oxygen is needed). Once all

386 sugars have been consumed, the stirring speed drops once again and $\mathrm{pH}$

387 increases rapidly. The sample taken at $21.6 \mathrm{~h}$ (the moment at which the

388 agitation decreased to a lower plateau) shows that no glucose was left, while

389 about $10 \mathrm{~g} / \mathrm{L}$ xylose and $2 \mathrm{~g} / \mathrm{L}$ arabinose still remained in the medium. Glucose

390 consumption rate was higher than $11 \mathrm{~g} /($ L.h) (all the glucose had been

391 consumed in the $1 \mathrm{~h}$ sampling interval), while xylose and arabinose were

392 consumed at a rate of $5.5 \mathrm{~g} /($ L.h $)$ and $2.5 \mathrm{~g} /($ L.h $)$, respectively. At $23 \mathrm{~h}$ a

393 second pulse of sugars was added with similar results.

394 To find adequate sugar concentrations to initiate the batch period, two

395 cultivations were started with $30 \mathrm{~g} / \mathrm{L}$ glucose $+15 \mathrm{~g} / \mathrm{L}$ xylose and $52 \mathrm{~g} / \mathrm{L}$ glucose

$396+26 \mathrm{~g} / \mathrm{L}$ xylose, respectively. The ratio glucose/xylose chosen was 2 since this

397 is the average ratio present in the WSHs used. The bioreactor was seeded with

398 a $10 \%(\mathrm{v} / \mathrm{v})$ inoculum grown for $12 \mathrm{~h}$ in $20 \mathrm{~g} / \mathrm{L}$ glucose. A concentrated mixed

399 solution of glucose $(440 \mathrm{~g} / \mathrm{L})$ and xylose $(180 \mathrm{~g} / \mathrm{L})$ was manually fed in $50 \mathrm{~mL}$

400 pulses from the moment the initial sugars were depleted until around $12 \mathrm{~h}$ of

401 culture. Subsequently automatic feeding.of the same solution was switched on

402 (DO-stat). The maximum specific growth rate of the assay that started with less

403 sugar was $0.27 \mathrm{~h}^{-1}$. The assay which was initiated with a higher sugar

404 concentration was probably subjected to substrate inhibition, since a $10 \mathrm{~h}$ lag

405 was observed after which the culture also reached a similar maximum specific

406 rate growth rate $\left(\mu_{\max }=0.28 \mathrm{~h}^{-1}\right)$. To avoid the lag period obtained at higher

407 sugar concentrations, thus resulting in lower productivities, subsequent

408 cultivations were started with lower sugar concentrations ( $30 \mathrm{~g} / \mathrm{L}$ glucose, 15

$409 \mathrm{~g} / \mathrm{L}$ xylose and $2.5 \mathrm{~g} / \mathrm{L}$ arabinose). 
411 The fed-batch mode of operation was carried out using an automated C-

412 source feeding regime based on the decrease of the stirring speed which

413 happens due to an automatic increase of the dissolved oxygen concentration

414 after $\mathrm{C}$-source exhaustion (DO stat). However, since the rate of glucose

415 consumption is higher than that observed for xylose or arabinose, a drop in

416 stirring speed will immediately occur upon glucose exhaustion, leading to xylose

417 and arabinose accumulation in the cultivation medium. In order to allow for the

418 consumption of the two pentoses, one of two strategies can be adopted, i.e. (i):

419 the stirring speed at which feed is triggered is set at a lower value, allowing for

420 xylose and arabinose consumption to take place, or (ii) the stirring speed trigger

421 is kept high and only glucose is totally consumed, allowing the other two sugars

422 to accumulate before inhibitory concentrations are reached; feeding can then be

423 stopped to allow for complete consumption of xylose and arabinose.

424 Different stirring speed values that trigger automatic feeding were tested

425 and a value of $900 \mathrm{rpm}$ was selected. This value enabled for complete

426 consumption of the glucose in the medium and for partial consumption of xylose

427 and arabinose before another pulse of fresh feed was added. The developed

428 strategy fully succeeded in avoiding the accumulation of xylose and arabinose

429 in the cultivation medium to inhibitory levels.

430 Cell growth and polymer production in fed-batch cultivations: wheat straw

431 hydrolysates versus commercial sugar mixture

432 To evaluate WSH as a carbon source, B. sacchari was thus cultivated in

433 2L controlled stirred-tank reactors (STRs) operated in the fed-batch mode. A 
434 control cultivation was carried out using a sugar blend of glucose, xylose and

435 arabinose in which the ratio glucose:xylose:arabinose is the average ratio

436 present in the wheat straw hydrolysates; i.e. 12: 6: 1. The results are shown in

437 Fig 4. The initial sugar composition in the batch phase was $23 \mathrm{~g} / \mathrm{L}$ glucose, 11.5

$438 \mathrm{~g} / \mathrm{L}$ xylose and $1.9 \mathrm{~g} / \mathrm{L}$ arabinose. The initial OD of the culture medium was

439 approximately 1.0 . Cells grew exponentially until circa $14 \mathrm{~h}$ at a $\mu_{\max }$ of $0.31 \mathrm{~h}^{-1}$.

440 During the exponential growth phase a $50 \mathrm{~mL}$ pulse of feed containing $560 \mathrm{~g} / \mathrm{L}$

441 glucose, $280 \mathrm{~g} / \mathrm{L}$ xylose and $46 \mathrm{~g} / \mathrm{L}$ arabinose was added. Cells started to

442 accumulate $\mathrm{P}(3 \mathrm{HB})$ prior to the exhaustion of phosphate in the medium ( $\mathrm{t}=14 \mathrm{~h}$ )

443 probably due to oxygen limitation. In fact, in less than $11 \mathrm{~h}$ (Fig. 4), the

444 volumetric rate of oxygen consumption was higher than the maximum rate of

445 oxygen transfer to the medium. This can be explained by the high metabolic

446 activity of this strain during glucose uptake and by the maximum allowed stiring

447 speed of $1200 \mathrm{rpm}$ of the bioreactor system. Higher productivities could be

448 obtained if the biomass could grow exponentially before reaching P-limiting

449 values. This would involve strategies such as the use of pure oxygen which are

450 expensive at production scale. After $\mathrm{P}$ exhaustion the fermentation proceeded

451 until approximately $40 \mathrm{~h}$ when the $\mathrm{P}(3 \mathrm{HB})$ cell content achieved a constant

452 value of circa $60 \%(\mathrm{~g} \mathrm{P}(3 \mathrm{HB}) / \mathrm{g}$ cell). The yield of polymer on total sugar

453 consumed ( $\left.Y_{P / S}\right)$ was $0.17 \mathrm{~g} / \mathrm{g}$ and the productivity (Prod ${ }_{v o l}$ ) was $1.6 \mathrm{~g} /($ L.h).

454 The first WSH tested in the STR was hydrolysate B (Table 1), an

455 evaporation-concentrated hydrolysate with higher sugar concentrations required

456 for the fed-batch operation. This hydrolysate, containing $468 \mathrm{~g} / \mathrm{L}$ glucose, 199

$457 \mathrm{~g} / \mathrm{L}$ xylose and $43 \mathrm{~g} / \mathrm{L}$ arabinose, was used as feed. The same hydrolysate was

458 diluted approximately 25 times to be used as C-source during the batch phase 
459 (concentrations of glucose, xylose and arabinose of $18.4,6.9$ and $0.9 \mathrm{~g} / \mathrm{L}$,

460 respectively). The cultivation was stopped at 21 hours due to a slowdown of the

461 biomass growth and $\mathrm{P}(3 \mathrm{HB}$ ) production (Fig. 5, 1a and 1b). At this point the

462 CDW reached $32.4 \mathrm{~g} / \mathrm{L}$ and the $\mathrm{P}(3 \mathrm{HB})$ concentration was $12.2 \mathrm{~g} / \mathrm{L}$. The yield of

463 polymer on total sugar consumed ( $\left.\mathrm{Y}_{\mathrm{P} / \mathrm{S}}\right)$ was $0.20 \mathrm{~g} / \mathrm{g}$, the volumetric

464 productivity (Prod ${ }_{\text {vol }}$ ) was $0.6 \mathrm{~g} /(\mathrm{L} . \mathrm{h}$ ) and the polymer accumulated in the cells

465 was $38 \%(\mathrm{~g} \mathrm{P}(3 \mathrm{HB}) / \mathrm{g} \mathrm{CDW})$. The reason for these deceiving results can be

466 ascribed to the high concentration of citrate present in this WSH ( $>50 \mathrm{~g} / \mathrm{L}$, Table

467 1). Consumption of citrate results in a $\mathrm{pH}$ increase of the broth, which in turn

468 interferes with the $\mathrm{pH}$ control. During the course of the fermentation, control of

469 the medium $\mathrm{pH}$ is achieved by adding ammonia hydroxide $\left(\mathrm{NH}_{4} \mathrm{OH}\right)$, which is

470 also used to supply nitrogen to the culture. As the fermentation proceeds, the

$471 \mathrm{pH}$ increases due to the citrate consumption, resulting in a lack of ammonia, In

472 fact, previous experiments have revealed that when using ammonia limitation in

473 addition to phosphate limitation, both cell growth and polymer production stop

474 (data not shown). During the production of hydrolysates at biorefinery.de,

$475 \mathrm{GmbH}$, citrate was used as buffer for the enzymatic step. Taking into account

476 the above mentioned results, the WSHs producer has subsequently changed

477 the hydrolysis process and was able to supply WSHs containing less than $5 \mathrm{~g} / \mathrm{L}$

478 of citrate (hydrolysates $\mathrm{C}$ to $\mathrm{H}$ on Table 1 ). Hydrolysate $\mathrm{C}$ containing only a

479 citrate concentration of $3.3 \mathrm{~g} / \mathrm{L}$ was tested next. The initial sugar composition of

480 the medium in the batch phase $(23 \mathrm{~g} / \mathrm{L}$ glucose, $11.7 \mathrm{~g} / \mathrm{L}$ xylose and $1.9 \mathrm{~g} / \mathrm{L}$

481 arabinose) was obtained through dilution of the hydrolysate. Cultivation started

482 with an initial OD of 1.3 (Fig. 5, 2a and 2b). Cells grew exponentially until

483 approximately $15 \mathrm{~h}$ with a $\mu_{\max }=0.28 \mathrm{~h}^{-1}$. After $12 \mathrm{~h}$ of cultivation a pulse of feed 
484 (hydrolysate C) containing $562.7 \mathrm{~g} / \mathrm{L}$ glucose, $283.6 \mathrm{~g} / \mathrm{L}$ xylose and $45.6 \mathrm{~g} / \mathrm{L}$ 485 arabinose was added, after which the addition of feed proceeded automatically 486 whenever the stirring speed dropped below $900 \mathrm{rpm}$. At this point, glucose was 487 exhausted, while xylose and arabinose were still present in the cultivation 488 media. Following P- exhaustion, polymer accumulation occurred until the end of 489 the cultivation (approx. $39 \mathrm{~h}$ ) to a maximum value of $83 \mathrm{~g} / \mathrm{L}$, corresponding to an 490 accumulation in the cells of $56 \%$. The yield of polymer on total sugar consumed 491 ( $\mathrm{Y}_{\mathrm{P} / \mathrm{sugar}}$ ) was $0.20 \mathrm{~g} / \mathrm{g}$. The productivity at the end of the cultivation was 1.5 $492 \mathrm{~g} /($ L.h $)$. These values are similar to the results obtained with the mixture of 493 commercial sugars used as control. In both cases, after $40 \mathrm{~h}$ of cultivation, the 494 consumed xylose is approximately $80 \%$ of the total amount of xylose that was 495 fed whereas this value is circa $95 \%$ for glucose. These figures clearly indicate 496 the ability of the system to promote the consumption of both sugars and 497 circumvent the accumulation of pentoses to inhibitory levels when an 498 appropriate feeding procedure is applied.

$499 \quad$ Very high productivities were attained using these improved hydrolysates 500 compared to the results obtained by other authors. Silva et al. (2004) working in 501 fed-batch conditions with this strain and a blend of glucose and xylose as feed 502 (330 g/L glucose and $360 \mathrm{~g} / \mathrm{L}$ xylose, mimicking the glucose / xylose ratio 503 present in the bagasse hydrolysates) achieved a biomass concentrations of 60 $504 \mathrm{~g} / \mathrm{L}$ containing $58 \% \mathrm{P}(3 \mathrm{HB})$ and a maximum $\mathrm{P}(3 \mathrm{HB})$ productivity of $0.47 \mathrm{~g} / \mathrm{L} . \mathrm{h}$ 505 only. The results presented herein demonstrate (i) the scale-up potential of the 506 developed fed-batch strategy, and (ii) the possibility of achieving high

507 biopolyester productivities based on hydrolysates produced from agricultural 508 residues (WSHs) as carbon source. Moreover, the WSHs produced by 
509 biorefinery.de GmbH using the AFEX technology can be directly used as C-

510 source in bacterial cultivations without the requirement of additional processing,

511 namely activated charcoal treatment for the elimination of toxic compounds [9].

512 Further batches of WSH (Table 1, hydrolysates $\mathrm{D}$ to $\mathrm{H}$ ) were finally tested as C-

513 source for growth and $\mathrm{P}(3 \mathrm{HB})$ production. The results are shown in Fig.6.

514 Maximum cell dry weight and $\mathrm{P}(3 \mathrm{HB})$ cell content ranged between 100-140 g/L

515 and $45-68 \%$, respectively. The yield of polymer on total sugars consumed and

516 the volumetric productivities varied between 0.16 and $0.22 \mathrm{~g} / \mathrm{g}$ and between 1.3

517 and $1.5 \mathrm{~g} / \mathrm{L} . \mathrm{h}$, respectively. The highest productivity $(1.6 \mathrm{~g} /(\mathrm{L} . \mathrm{h}))$ and product

518 yield on sugar $(0.22 \mathrm{~g} / \mathrm{g})$ were achieved with hydrolysate $\mathrm{E}$. In this cultivation,

519 total xylose and glucose consumptions of $92.0 \%$ and $99.5 \%$ respectively, were

520 achieved. The lowest productivities (1.3 g/(L.h)) were obtained with

521 hydrolysates $\mathrm{G}$ and $\mathrm{H}$. In these hydrolysates, the ratio of concentrations

522 glucose/xylose varies between 1.2 and 1.4 which is lower compared to the ratio

523 of sugar concentrations found in hydrolysate $E$ (glucose/xylose $\approx 2$ ). A lower

524 glucose/xylose ratio influences the frequency of feed additions, i.e. feed

525 triggering becomes less frequent since the overall rate of sugar consumption is

526 lower at higher xylose concentrations. It is however difficult to circumvent

527 process variability when using agriculture-derived C-sources such as WSH,

528 since the composition of these materials depends on a variety of factors,

529 including soil quality, climate and weather conditions, and harvest time.

\section{Conclusions}

531 Fed-batch cultivation strategies of Burkholderia sacchari DSM 17165 were

532 developed in order to attain high $\mathrm{P}(3 \mathrm{HB})$ cell contents and productivities on 
533 wheat straw hydrolysates. A polymer cell content of $72 \% \mathrm{~g} / \mathrm{g}$ and a maximum

534 volumetric productivity of $1.6 \mathrm{~g} /($ L.h) were achieved using WSHs rich in glucose,

535 xylose and arabinose as carbon sources in a basal mineral medium. The

536 polymer yield on total sugar consumed $\left(Y_{P / s u g a r}\right)$ was $0.22 \mathrm{~g} / \mathrm{g}$. At the end of the

537 cultivations, maximum glucose and xylose consumptions were over $99 \%$ and 90

$538 \%$, respectively. The proposed feeding procedure was indeed able to overcome

539 the carbon catabolite repression phenomenon associated to the presence of

540 multiple sugars, allowing for an efficient consumption of the pentoses and

541 hexoses present in the hydrolysate.

542 Based on a lignocellulosic agricultural residue, a fed-batch cultivation

543 process for $\mathrm{P}(3 \mathrm{HB})$ production featuring significantly high productivities and

544 conversion yields is for the first time described.

545

546

$547 \quad$ Acknowledgements

548 This work has received funding from the European Union $7^{\text {th }}$ Framework

549 Programme (FP7/2007-2013) under Grant Agreement number 246449

550 'BUGWORKERS'. The authors would like to acknowledge biorefinery.de GmbH

551 (Germany) for providing the hydrolysates and Fundação para a Ciência e

552 Tecnologia, Portugal for financial support (fellowships SFRH/BPD/68587/2010

553 and SFRH/BPD/26678/2006).

554

555 
[1] Anderson AJ, Dawes EA. Occurrence, Metabolism, Metabolic Role, and Industrial Uses of Bacterial Polyhydroxyalkanoates. Microbiological Reviews 1990;54:450-472.

[2] Kim BS, Lee SC, Lee SY, Chang HN, Chang YK, Woo SI. Production of poly(3-hydroxybutyric acid) by fed-batch culture of $<1>$ Alcaligenes eutrophus $</ \mid>$ with glucose concentration control. Biotechnology and Bioengineering 1994;43:892-898.

[3] Steinbüchel A. PHB and other polyhydroxyalkanoic acids. In: R. Rehm HJ,M. Galbe editors. Biotechnology products of primary metabolism vol. vol. 6 . Weinheim: Biotechnology VCH; 1996. p. 404-464.

[4] Choi J-i, Lee SY. Process analysis and economic evaluation for Poly(3-hydroxybutyrate) production by fermentation. Bioprocess and Biosystems Engineering 1997;17:335-342.

[5] Cavalheiro JMBT, de Almeida MCMD, Grandfils C, da Fonseca MMR. Poly(3hydroxybutyrate) production by Cupriavidus necator using waste glycerol. Process Biochemistry 2009;44:509-515.

[6] Pais J, Farinha I, Serafim LS, Prieto MA, Arévalo-Rodríguez M, Reis MAM. Bioplastics production from cheese whey by recombinant E. coli. New Biotechnology 2009;25:S220-S220.

[7] Kenny ST, Nikodinovic- Runic J, Kaminsky W, Woods T, Babu RP, Keely CM, Blau W, O'Connor KE. Up-Cycling of PET (Polyethylene Terephthalate) to the Biodegradable Plastic PHA (Polyhydroxyalkanoate). Environ Sci Technol 2008;42:7696-7701.

[8] Yu J, Stahl H. Microbial utilization and biopolyester synthesis of bagasse hydrolysates. Bioresource Technology 2008;99:8042-8048.

[9] Silva LF, Taciro MK, Michelin Ramos ME, Carter JM, Pradella JGC, Gomez JGC. Poly-3hydroxybutyrate (P3HB) production by bacteria from xylose, glucose and sugarcane bagasse hydrolysate. Journal of Industrial Microbiology \& Biotechnology 2004;31:245254.

[10] Silva JA, Tobella LM, Becerra J, Godoy F, Martínez MA. Biosynthesis of poly-[beta]hydroxyalkanoate by Brevundimonas vesicularis LMG P-23615 and Sphingopyxis macrogoltabida LMG 17324 using acid-hydrolyzed sawdust as carbon source. Journal of Bioscience and Bioengineering 2007;103:542-546.

[11] Keenan TM, Nakas JP, Tanenbaum SW. Polyhydroxyalkanoate copolymers from forest biomass. J Ind Microbiol Biotechnol 2006;33:616-626.

[12] Du C, Sabirova J, Soetaert W, Lin KSC. Polyhydroxyalkanoates Production From Low-cost Sustainable Raw Materials. Current Chemical Biology 2012;6:14-25.

[13] Kamm B, Kamm M, Schmidt M, Starke I, Kleinpeter E. Chemical and biochemical generation of carbohydrates from lignocellulose-feedstock (Lupinus nootkatensis)-quantification of glucose. Chemosphere 2006;62:97-105.

[14] Bledzki AK, Mamun AA, Volk J. Physical, chemical and surface properties of wheat husk, rye husk and soft wood and their prolypropylene composites. Composites Part A 2010; 41:480-488.

[15] Kim S, Dale BE. Global potential bioethanol production from wasted crops and crop residues. Biomass and Bioenergy 2004; 26:361 - 375.

[16] Teymouri F, Laureano-Perez L, Alizadeh H, Dale BE. Optimization of the ammonia fiber explosion (AFEX) treatment parameters for enzymatic hydrolysis of corn stover. Bioresource Technology 2005;96:2014-2018.

[17] Bals B, Rogers C, Jin M, Balan V, Dale B. Evaluation of ammonia fibre expansion (AFEX) pretreatment for enzymatic hydrolysis of switchgrass harvested in different seasons and locations. Biotechnology for Biofuels 2010;3:1-11. 
604

[18] Mosier N, Wyman C, Dale B, Elander R, Lee YY, Holtzapple M, Ladisch M. Features of promising technologies for pretreatment of lignocellulosic biomass. Bioresource Technology 2005;96:673-686.

[19] Dale BE, Leong CK, Pham TK, Esquivel VM, Rios I, Latimer VM. Hydrolysis of lignocellulosics at low enzyme levels: Application of the AFEX process. Bioresource Technology 1996;56:111-116.

[20] McMillan JD. Pretreatment of lignocellulosic biomass. In: M. E. Himmel, J. O. Baker,R. P. Overend editors. Enzymatic Conversion of Biomass for Fuels Production. Washington, DC: American Chemical Society; 1994. p. 292-324.

[21] Bramer CO, Vandamme P, Silva LFd, Gomez JGC, Steinbuchel A. Burkholderia sacchari sp. nov., a polyhydroxyalkanoate-accumulating bacterium isolated from soil of a sugarcane plantation in Brazil. International Journal of Systematic and Evolutionary Microbiology 2001;51:1709-1713.

[22] Leiß S. Biorefining of lignocellulosic feedstock by AFEX-pretreatment and enzymatic hydrolysis for production of fermentable sugar- biorefinery.de $\mathrm{GmbH}$. German Russian Forum Biotechnology Hannover-Germany, http://owwz.de/fileadmin/Biotechnologie/BioVeranst/Biotechnica2011/Programme H omepage.pdf; 2011.

[23] Cavalheiro JMBT, Raposo RS, de Almeida MCMD, Cesário MT, Sevrin C, Grandfils C, da Fonseca MMR. Effect of cultivation parameters on the production of poly(3hydroxybutyrate-co-4-hydroxybutyrate) and poly(3-hydroxybutyrate-4hydroxybutyrate-3-hydroxyvalerate) by Cupriavidus necator using waste glycerol. Bioresource Technology 2012;111:391-397.

[24] Greenberg AE, Clesceri LS, Eaton AD. editors. Standard Methods for the Examination of Water and Wastewater New York: American Public Health Association; 1992.

[25] Lee D, Owens VN, Boe A, Jeranyama P. Composition of Herbaceous Biomass Feedstocks: South Dakota State University; 2007.

[26] Lopes M, Rocha R, Zanotto S, Gomez J, Silva L. Screening of bacteria to produce polyhydroxyalkanoates from xylose. World Journal of Microbiology and Biotechnology 2009;25:1751-1756.

[27] Lopes M, Gosset G, Rocha R, Gomez J, Ferreira da Silva L. PHB biosynthesis in catabolite repression mutant of Burkholderia sacchari. Current Microbiology 2011;63. 
638 Table 1: Composition of the different batches of WSH delivered by

639 biorefinery.de GmbH (Germany).

640 Table 2: Overview of the strains reported in literature able to metabolize xylose 641 and produce $\mathrm{P}(3 \mathrm{HB})$.

642 Table 3: Cultivation parameters of $\mathrm{P}(3 \mathrm{HB})$ production by Burkholderia sacchari

643 Table 4: Growth and $\mathrm{P}(3 \mathrm{HB})$ production of $B$. sacchari in shake flask cultures

644 on Hydrolysate A, 2 fold diluted Hydrolysate A and simulated Hydrolysate A (all

645 the values refer to the time for maximum polymer concentration).

646 
647 Figure 1: Growth and $\mathrm{P}(3 \mathrm{HB})$ production of $B$. sacchari at different sugar

648 concentrations: A: $10 \mathrm{~g} / \mathrm{L}$ glucose; B: $10 \mathrm{~g} / \mathrm{L}$ xylose; C: $10 \mathrm{~g} / \mathrm{L}$ glucose $+10 \mathrm{~g} / \mathrm{L}$

649 xylose.CDW $(-), \mathrm{P}(3 \mathrm{HB})\left({ }^{-}\right)$, glucose $\left(-\frac{-}{-}\right)$ and xylose $(*)$ ).

650 Figure 2: Growth, $\mathrm{P}(3 \mathrm{HB})$ production and sugar consumption in a) Hydrolysate

651 A , b) mix of commercial sugars and c) 2x diluted Hydrolysate A:CDW (-),

652 P3HB ( -+$)$, glucose $(\triangle)$, xylose $(*)$ ) and arabinose $(\Theta)$.

653 Figure 3: B. sacchari fed-batch cultivation data for growth and production using

654 a blend of glucose (9 g/L), xylose (8 g/L) and arabinose $(2 \mathrm{~g} / \mathrm{L})$ as C-sources:

655 CDW $(-)$, $\mathrm{P}(3 \mathrm{HB})\left({ }^{-}\right)$, glucose $(-)$, xylose $(*)$ ), arabinose $(*)$,

656 citrate $(-\square-)$ phosphorous $(--)$, nitrogen $(\rightarrow)$, stirring speed, rpm $(\rightarrow$,

$657 \% \mathrm{DO}(-)$, volume feed, $\mathrm{mL}(-)$.

658 Figure 4: Cell growth, $\mathrm{P}(3 \mathrm{HB})$ production, $\mathrm{P}(3 \mathrm{HB})$ accumulation, consumption

659 of sugars, consumption of phosphate and data acquisition in a $2 \mathrm{~L}$ fed-batch

660 cultivation with $B$. sacchari using as feed a blend of sugars. CDW (

$661 \mathrm{P}(3 \mathrm{HB})\left({ }^{-}\right), \% \mathrm{P}(3 \mathrm{HB})(\stackrel{\Delta}{-})$, glucose $(--)$, xylose $\left({ }^{*}\right)$, arabinose

662 ( $*$ ), phosphate (- - ), \% DO (-), stirring speed, rpm ( - ) and volume 663 feed $(-)$.

664

665 Figure 5: Cell growth, $\mathrm{P}(3 \mathrm{HB})$ production, $\mathrm{P}(3 \mathrm{HB})$ accumulation and sugar,

666 citrate and phosphate consumption by $B$. sacchari in a $2 \mathrm{~L}$ fed-batch cultivation

667 using as feed 1a) and 1b): hydrolysate B and 2a) and $2 b$ ): hydrolysate C. CDW

$668(--), \mathrm{P}(3 \mathrm{HB})\left({ }^{-}\right), \% \mathrm{P}(3 \mathrm{HB})(\underline{-})$, glucose $\left(-{ }^{-}\right)$, xylose $\left({ }^{*}\right)$,

669 arabinose $(*)$ ), phosphate $(--)$ ) and citrate $(-\square-)$. 
670 Figure 6: Cell growth, $\mathrm{P}(3 \mathrm{HB})$ production and $\mathrm{P}(3 \mathrm{HB})$ accumulation by $B$.

671 sacchari in $2 \mathrm{~L}$ fed-batch fermentation using different batches of wheat straw

672 hydrolysate: $\mathrm{D}\left(\ulcorner-\mathrm{C}), \mathrm{E}\left({ }^{-}\right), \mathrm{F}(--), \mathrm{G}\left({ }^{-}\right)\right.$) and $\mathrm{H}\left(-{ }^{-}\right)$.

673

674

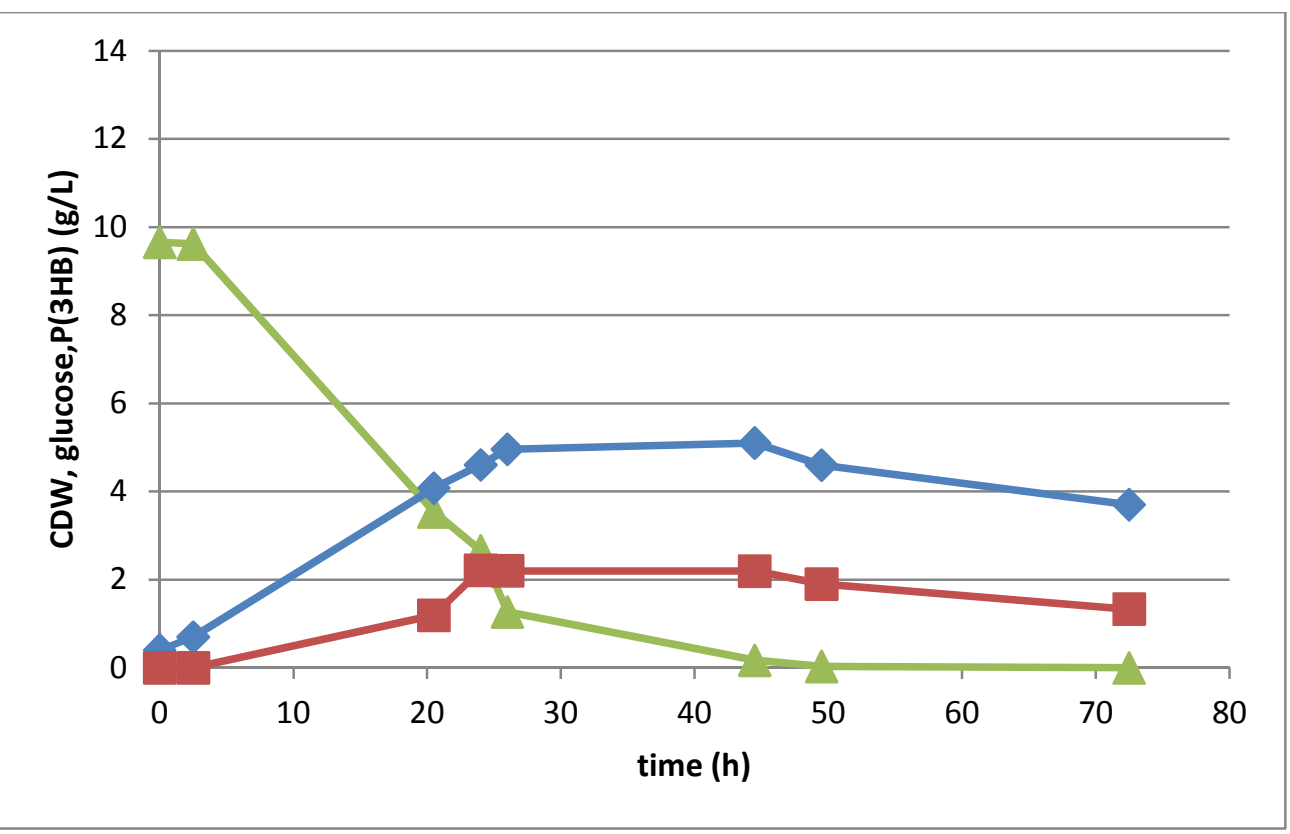

675

676 


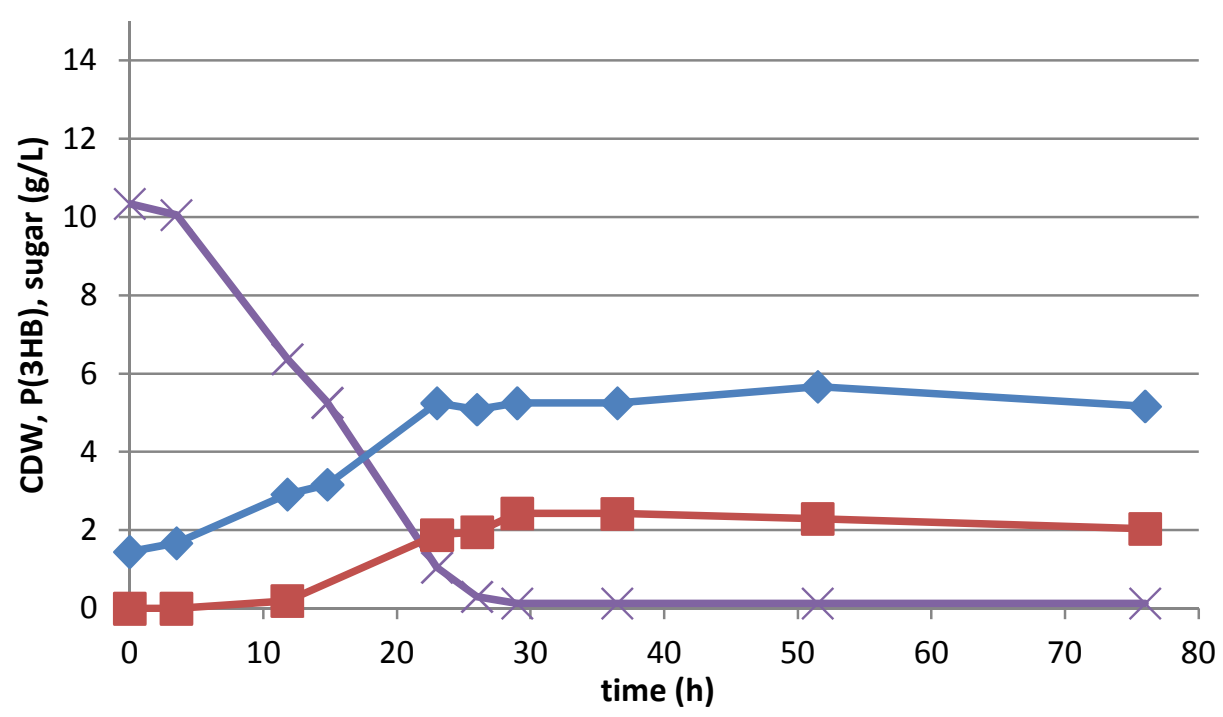

678

679

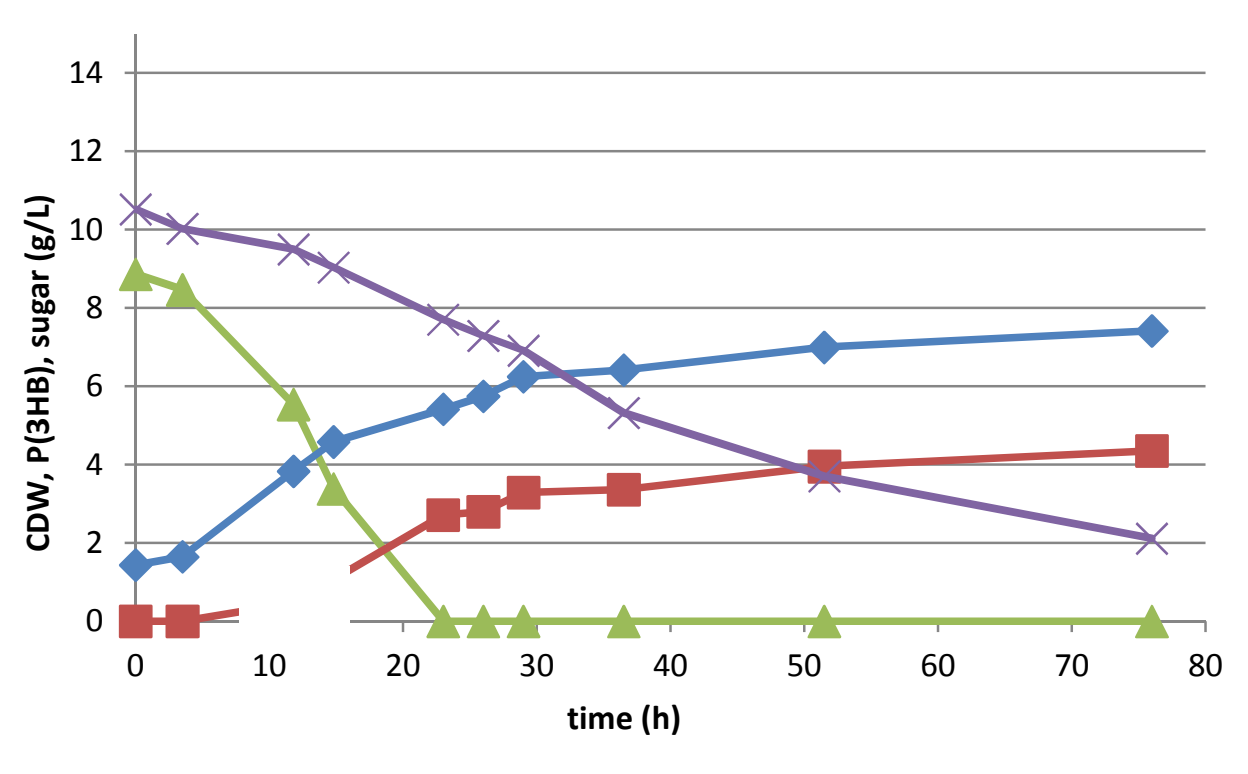

680 Fig 1

681 


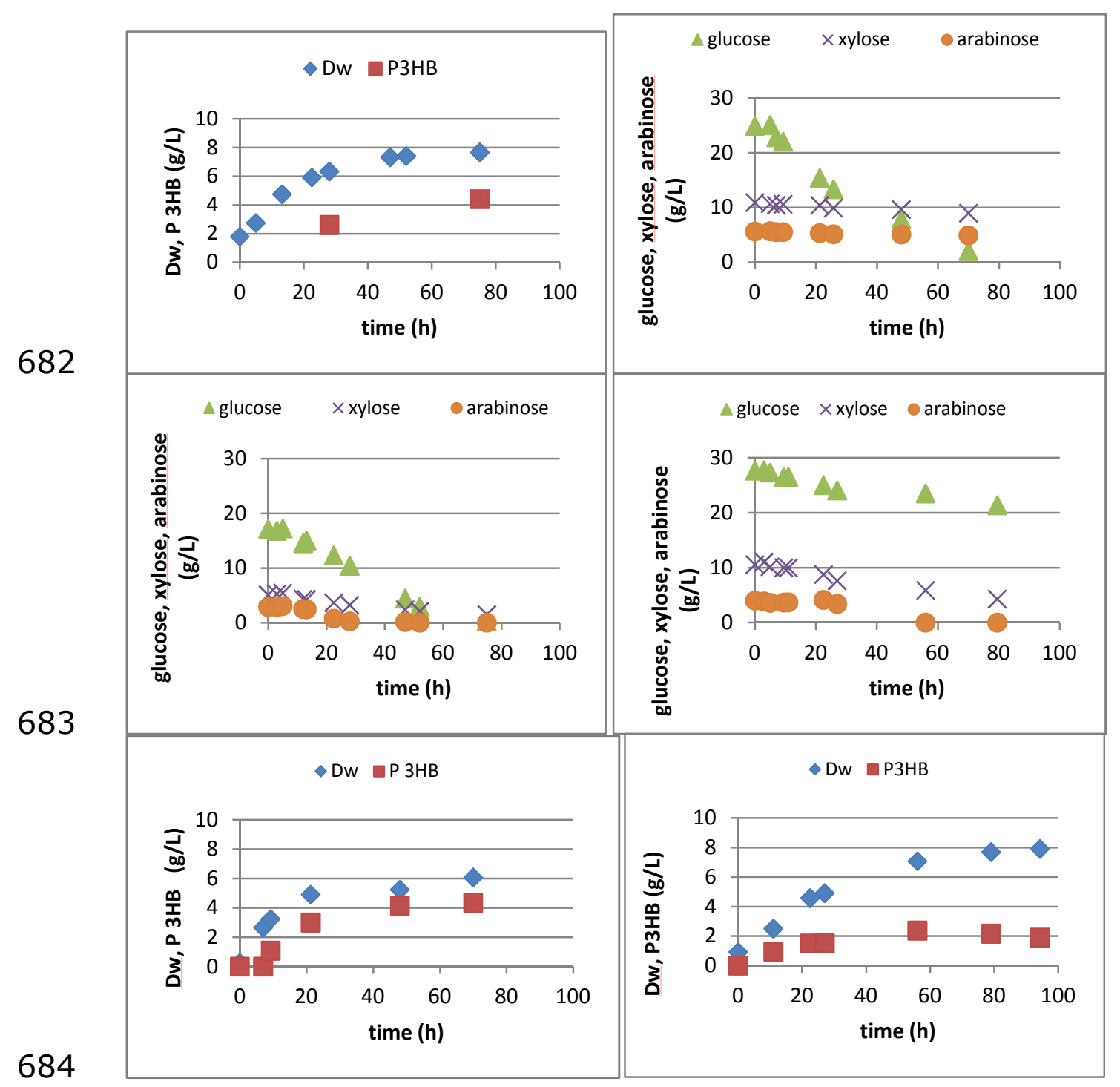

685 Fig 2

686 
687

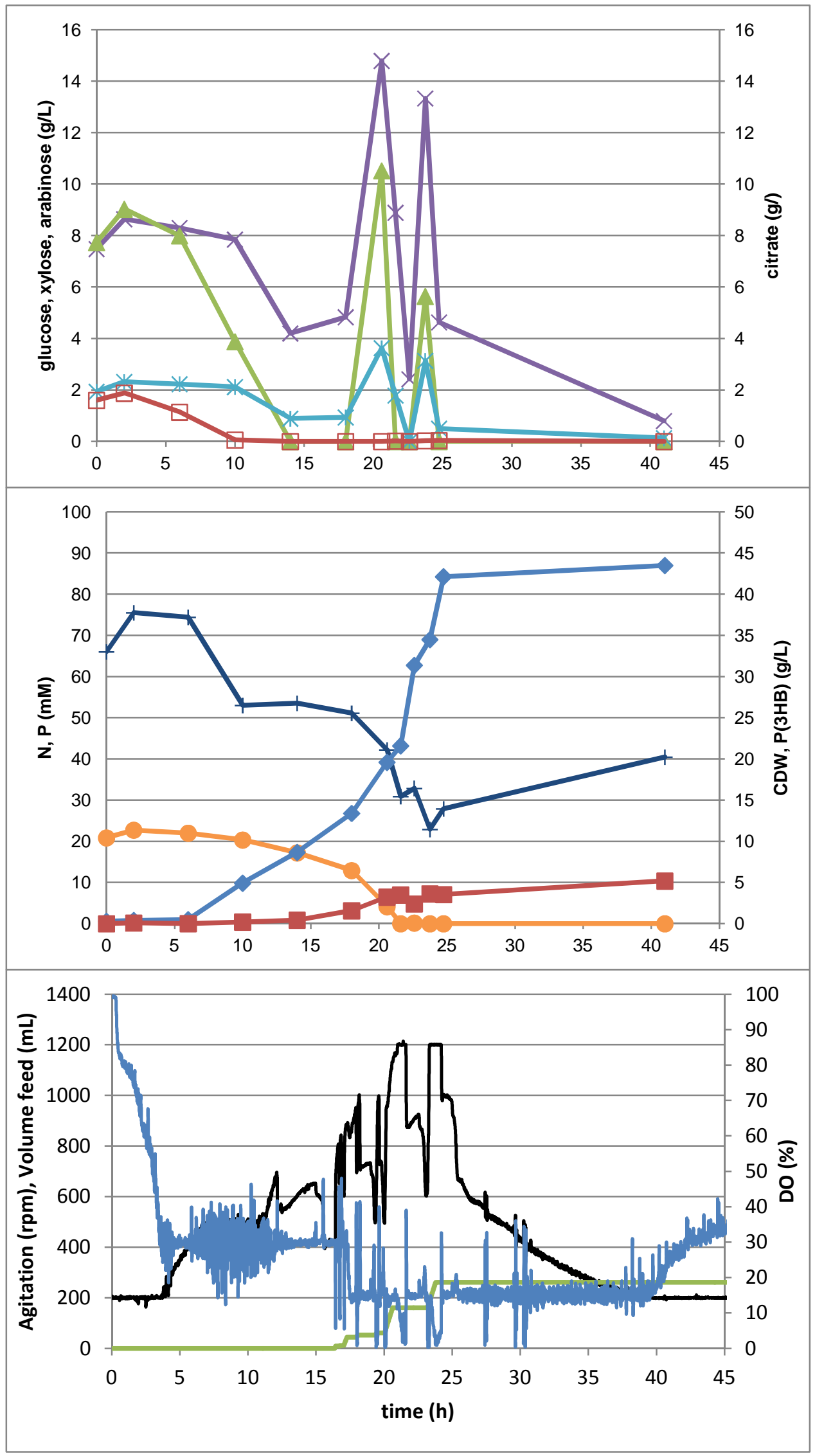

$690 \quad$ Fig 3 

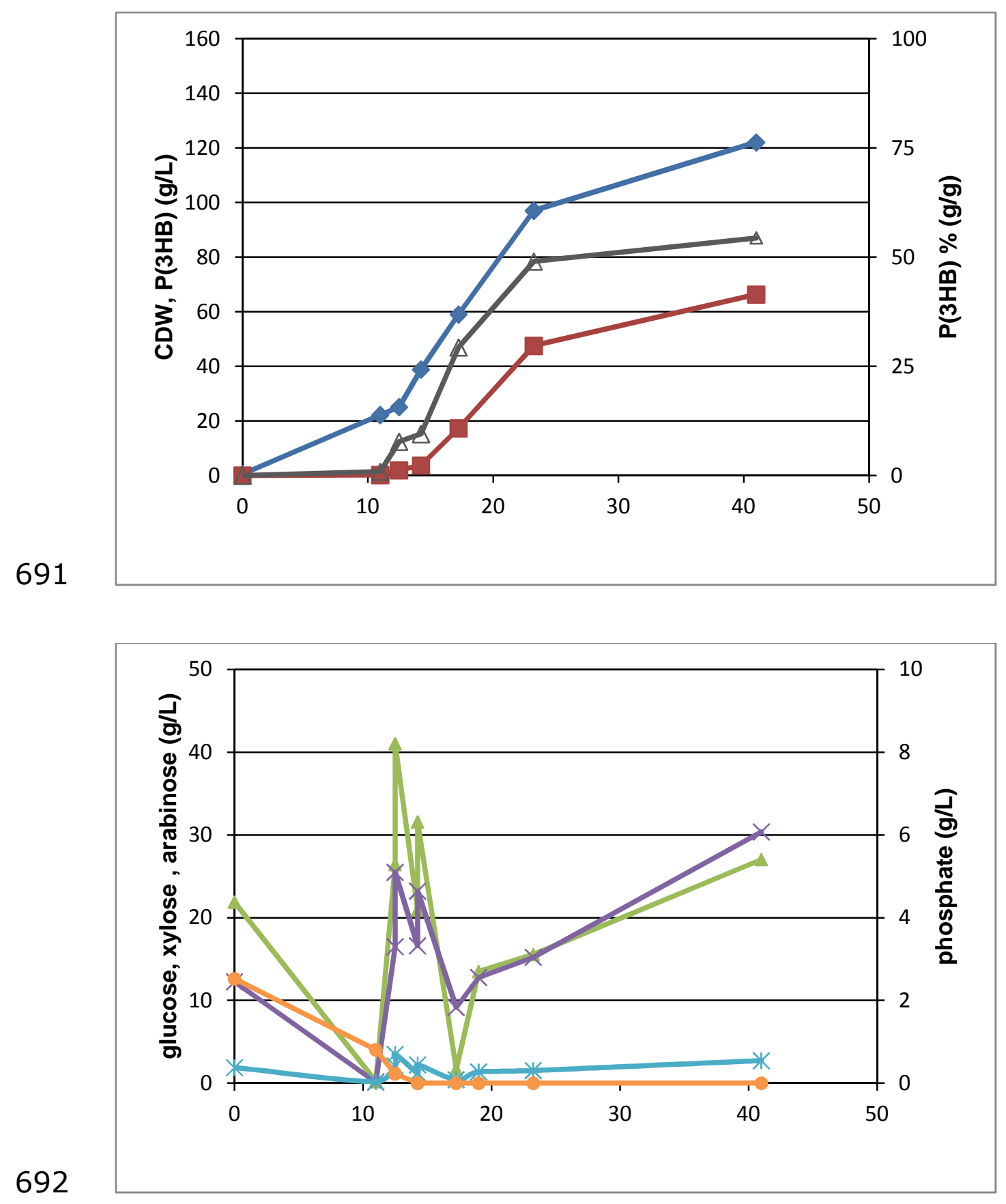
693

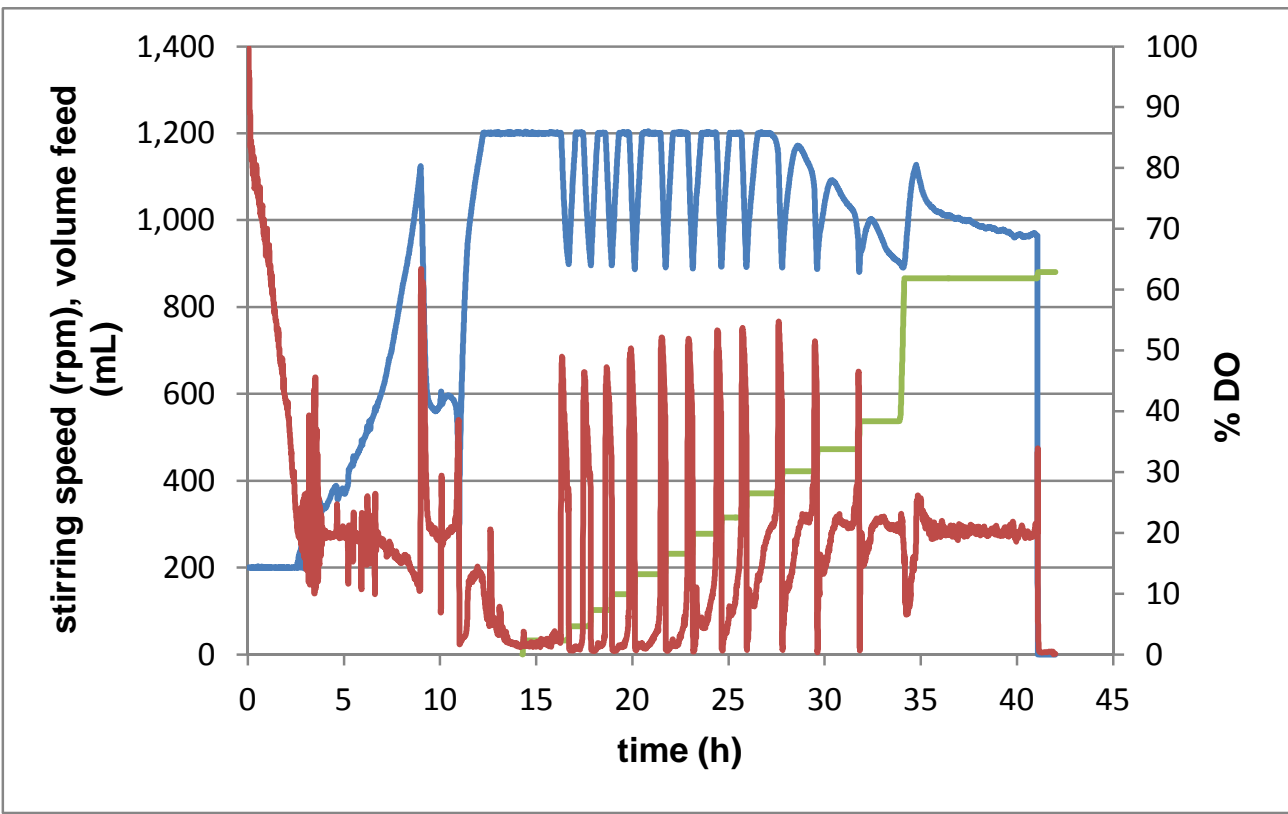

694 Fig 4

695
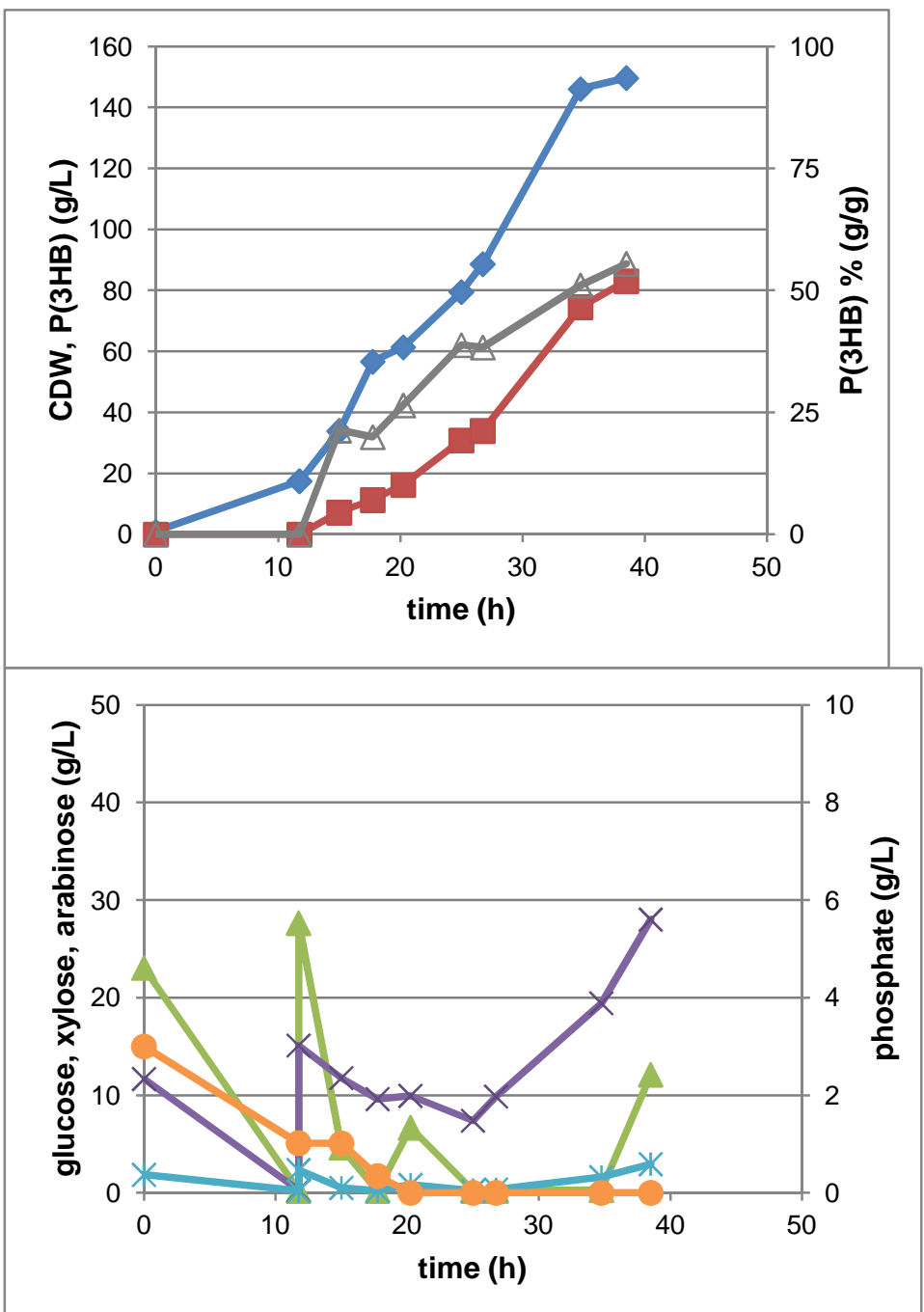

696 


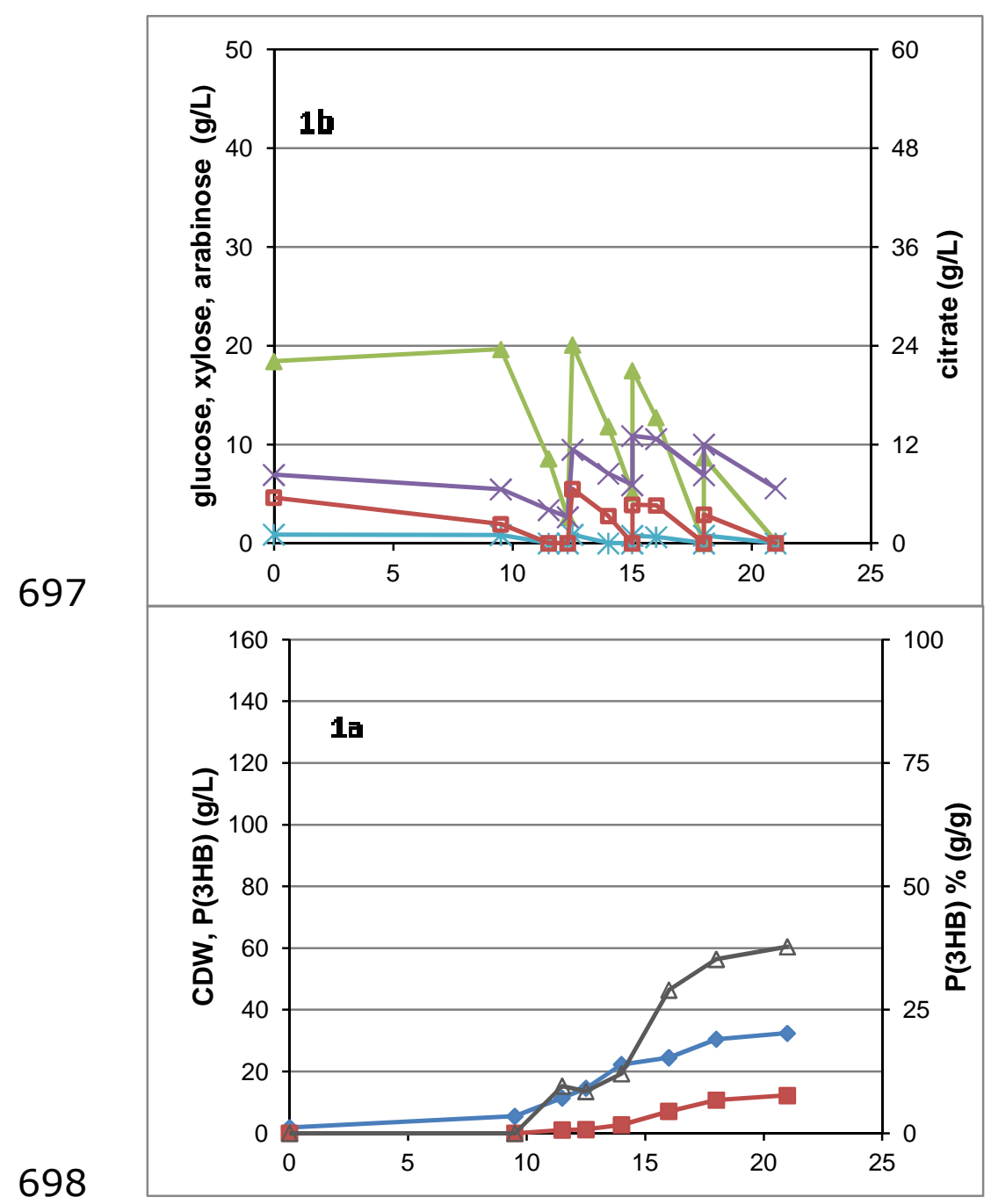

$699 \quad$ Fig 5

700 


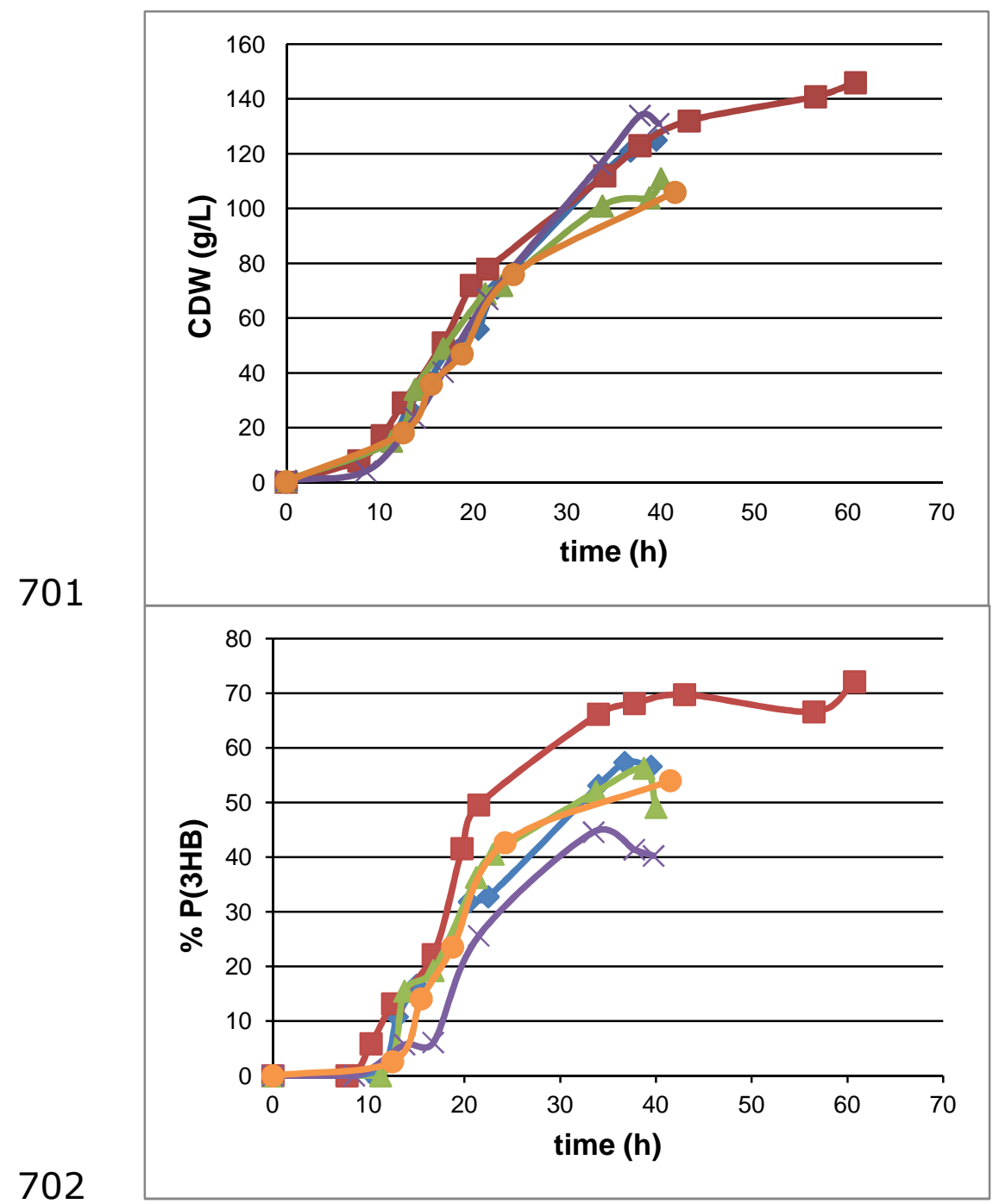

$703 \quad$ Fig 6

704 
Table 1:

\begin{tabular}{cccccc}
\hline $\begin{array}{c}\text { Batches } \\
\text { Hydrolysate }\end{array}$ & $\begin{array}{c}\text { Glucose } \\
(\mathrm{g} / \mathrm{L})\end{array}$ & $\begin{array}{c}\text { Xylose } \\
(\mathrm{g} / \mathrm{L})\end{array}$ & $\begin{array}{c}\text { Arabinose } \\
(\mathrm{g} / \mathrm{L})\end{array}$ & $\begin{array}{c}\text { Furfural } \\
(\mathrm{g} / \mathrm{L})\end{array}$ & $\begin{array}{c}\text { Citric acid } \\
(\mathrm{g} / \mathrm{L})\end{array}$ \\
\hline $\mathrm{A}$ & 32.4 & 12.9 & 4.5 & 0.10 & 3.10 \\
\hline $\mathrm{B}$ & 468.0 & 199.2 & 23.2 & 0.27 & 57.80 \\
\hline $\mathrm{C}$ & 562.7 & 283.6 & 45.6 & 0.01 & 3.30 \\
\hline $\mathrm{D}$ & 465.3 & 146.3 & 41.5 & 0.03 & 0.15 \\
\hline $\mathrm{F}$ & 628.3 & 314.8 & 47.6 & 0.01 & 0.90 \\
\hline $\mathrm{G}$ & 445.1 & 206.1 & 35.4 & $\mathrm{ND}$ & 0.02 \\
\hline H & 585.1 & 347.0 & 44.6 & 0.02 & 0.25 \\
\hline
\end{tabular}

Table 2

\begin{tabular}{|c|c|c|c|c|c|c|c|}
\hline Strain & $\underset{\left(h^{-1}\right)}{\mu \max }$ & $\begin{array}{l}\text { CDW } \\
(g / L)\end{array}$ & $\begin{array}{c}\mathrm{P}(3 \mathrm{HB}) \\
(\%)\end{array}$ & $\begin{array}{c}Y_{(\mathrm{P} 3 \mathrm{HB}) / \mathrm{xyl}} \\
(\mathbf{g} / \mathbf{g})\end{array}$ & $\begin{array}{c}\mathrm{q}_{\mathrm{P}(3 \mathrm{HB}) \max } \\
(\mathrm{g} / \mathrm{g} \cdot \mathrm{h})\end{array}$ & $\begin{array}{l}\text { Prod }_{\text {vol }} \\
\text { (g/L h) }\end{array}$ & Reference \\
\hline $\begin{array}{c}\text { Burkholderia } \\
\text { cepacia } \\
\text { ATCC } 17759\end{array}$ & 0.34 & 7.5 & 49 & 0.11 & 0.02 & - & [1] \\
\hline $\begin{array}{l}\text { Burkholderia } \\
\text { cepacia }\end{array}$ & - & - & 45 & 0.11 & 0.072 & - & [2] \\
\hline $\begin{array}{l}\text { Burkholderia } \\
\text { sacchari } \\
\text { IPT } 101\end{array}$ & - & 5.5 & 58 & 0.26 & - & 0.07 & [3] \\
\hline $\begin{array}{c}\text { Burkholderia } \\
\text { sacchari } \\
\text { LMF828 } \\
\text { (mutant PTS } \\
\text { glu+) } \\
\end{array}$ & 0.35 & 5.3 & 50 & 0.17 & - & 0.07 & [4] \\
\hline $\begin{array}{c}\text { E. coli } \\
\text { TG1(pSYL107) }\end{array}$ & - & 4.8 & 36 & - & - & 0.028 & [5] \\
\hline $\begin{array}{c}\text { Pseudomonas } \\
\text { pseudoflava } \\
\text { ATCC } 33668 \\
\end{array}$ & 0.13 & 4.0 & 22 & 0.04 & 0.03 & - & [6] \\
\hline $\begin{array}{c}\text { Isolated } \\
\text { bacterium strain } \\
\text { QN271 }\end{array}$ & - & 4.3 & 29 & - & - & 0.04 & [7] \\
\hline
\end{tabular}


[1] Young FK, Kastner JR, May SW. Microbial Production of Poly- $\beta$-Hydroxybutyric Acid from dXylose and Lactose by Pseudomonas cepacia. Applied and Environmental Microbiology 1994;60:4195-4198.

[2] Ramsay J, Hassan M, Ramsay B. Hemicellulose as a potential substrate for production of poly( $\beta$-hydroxyalkanoates). Canadian Journal of Microbiology 1995;41:262-266.

[3] Lopes M, Rocha R, Zanotto S, Gomez J, Silva L. Screening of bacteria to produce polyhydroxyalkanoates from xylose. World Journal of Microbiology and Biotechnology 2009;25:1751-1756.

[4] Lopes M, Gosset G, Rocha R, Gomez J, Ferreira da Silva L. PHB biosynthesis in catabolite repression mutant of Burkholderia sacchari. Current Microbiology 2011;63.

[5] Lee SY. Poly(3-hydroxybutyrate) production from xylose by recombinant Escherichia coli. Bioprocess Engineering 1998;18:397-399.

[6] Bertrand J, Ramsay B, Ramsay J, Chavarie C. Biosynthesis of Poly- $\beta$-Hydroxyalkanoates from Pentoses by Pseudomonas pseudoflava. Applied Environmental Microbiology 1990;56:3133-3138.

[7] Doan TV, Nguyen BT. Polyhydroxyalkanoates production by a bacterium isolated from mangrove soil samples collected from Quang Ninh province. Journal of Vietnamese Environment 2012;3:76-79.

710 Table 3

\begin{tabular}{|c|c|c|c|c|c|c|c|}
\hline $\begin{array}{l}\text { Carbon } \\
\text { source }\end{array}$ & $\begin{array}{l}\text { conc. } \\
\text { (g/L) }\end{array}$ & $\begin{array}{l}\text { time } \\
\text { (h) }\end{array}$ & $\begin{array}{l}\text { CDW } \\
(\mathrm{g} / \mathrm{L}) \\
\end{array}$ & $\begin{array}{c}\mathrm{P}(3 \mathrm{HB})_{\max } \\
(\mathrm{g} / \mathrm{L})\end{array}$ & $\begin{array}{c}\mathrm{Y}_{\mathrm{P} / \mathrm{s}} \\
\left(\mathrm{g}_{\mathrm{P}(3 \mathrm{HB})} / \mathrm{g}_{\text {sugar }}\right)\end{array}$ & $\begin{array}{c}\% \text { P3HB } \\
\left(g_{\mathrm{P}(3 \mathrm{HB})} / \mathrm{g}_{\mathrm{CDW}}\right)\end{array}$ & $\begin{array}{c}\text { Prod }_{\text {vol }} \\
\left(\mathrm{g}_{\mathrm{P}(3 \mathrm{HB})} / \mathrm{Lh}\right)\end{array}$ \\
\hline Glucose & 20 & 29 & 6.3 & 3.8 & 0.25 & 60.3 & 0.13 \\
\hline Xylose & 20 & 36.5 & 6.3 & 2.8 & 0.24 & 44.4 & 0.08 \\
\hline Arabinose & 20 & 51.5 & 7.4 & 4.7 & 0.24 & 62.0 & 0.09 \\
\hline Glucose & 10 & 26 & 5.0 & 2.2 & 0.26 & 44.0 & 0.09 \\
\hline Xylose & 10 & 29 & 5.2 & 2.4 & 0.24 & 46.7 & 0.08 \\
\hline Gluc + Xyl & $10+10$ & 76 & 7.4 & 4.4 & 0.25 & 58.9 & 0.06 \\
\hline
\end{tabular}


Table 4:

\begin{tabular}{|c|c|c|c|c|c|c|c|c|}
\hline Carbon source & $\begin{array}{c}\Delta S \\
(g / L)\end{array}$ & $\begin{array}{c}\mathrm{CDW}_{\max } \\
(\mathrm{g} / \mathrm{L})\end{array}$ & $\begin{array}{c}P(3 H B)_{\max } \\
(\mathrm{g} / \mathrm{L})\end{array}$ & $\begin{array}{l}X_{\text {res }} \\
(g / L)\end{array}$ & $\begin{array}{l}Y_{\text {Xres/s }} \\
\text { (g/g) }\end{array}$ & $\begin{array}{l}Y_{P / S} \\
(g / g)\end{array}$ & $\begin{array}{c}P(3 H B) \\
(\%)\end{array}$ & $\begin{array}{l}\text { time } \\
\text { (h) }\end{array}$ \\
\hline Hydrolysate A & 12.5 & 7.0 & 2.4 & 4.6 & 0.37 & 0.19 & 34 & 56 \\
\hline $\begin{array}{c}\text { Hydrolysate A } \\
\text { (2x dil) }\end{array}$ & 22.6 & 7.7 & 4.4 & 3.3 & 0.15 & 0.19 & 57 & 75 \\
\hline $\begin{array}{c}\text { Simulated } \\
\text { Hydrolysate A }\end{array}$ & 24 & 6.0 & 4.4 & 1.6 & 0.07 & 0.18 & 72 & 70 \\
\hline
\end{tabular}

714

715 